\title{
Importance of Regional Rainfall Data in Homogeneous Clustering of Data Sparse Areas: A Study in the Upper Brahmaputra Valley Region
}

Jayshree Hazarika ( $\square$ jayshree@iitg.ac.in )

Assam Engineering College https://orcid.org/0000-0002-7155-8752

Arup Kumar Sarma

Indian Institute of Technology Guwahati

\section{Research Article}

Keywords: Regionalization, L-moments, Fuzzy clustering, Homogeneity test

Posted Date: April 15th, 2021

DOl: https://doi.org/10.21203/rs.3.rs-349940/v1

License: (c) (1) This work is licensed under a Creative Commons Attribution 4.0 International License.

Read Full License 


\title{
Importance of Regional Rainfall Data in Homogeneous Clustering of Data
}

\section{Sparse Areas: A Study in the Upper Brahmaputra Valley Region}

\author{
Jayshree Hazarika $^{1,2}$, Arup Kumar Sarma ${ }^{1}$
}

${ }^{1}$ Department of Civil Engineering, Indian Institute of Technology Guwahati, Guwahati 781039, Assam, India

${ }^{2}$ Department of Civil Engineering, Assam Engineering College, Guwahati - 781013, Assam, India

Corresponding Author: Dr. Jayshree Hazarika

Email ID: jayshree@iitg.ac.in; ORCID ID: 0000-0002-7155-8752

\section{Abstract}

Delineation of homogeneous regions has found its way into many hydrological applications as it helps in addressing the challenges in understanding the behavior of rainfall distribution and its variability at a local scale. In the present study, rainfall data recoded by 83 tea gardens in the upper Brahmaputra valley region of Assam have been used to identify homogeneous rainfall regions by using fuzzy clustering analysis. Further, seven different cluster validity indices $(\mathrm{CVs})$ were utilized to find out the optimum clustering in the fuzzy c-means (FCM) algorithm. The clusters thus formed were assessed for statistical homogeneity by performing homogeneity tests based on L-moment. Three different combinations of feature vectors were employed in FCM algorithm and the outputs were compared for attaining best solutions to regionalization. The results were further compared with previous regionalization studies. The analysis and comparison conclude that if regionalization needs to be done at a local scale, further sub-clustering of a larger clustered region to smaller regions may be required. Local rainfall data can be used for the purpose provided a good dataset with large number of station points are available within the region. Along with rainfall data, geographical location 
25 parameters (latitude, longitude and elevation) need to be taken into account for getting a 26 definite conclusion

27

28 Keywords:

29 Regionalization, L-moments, Fuzzy clustering, Homogeneity test

30 


\section{Introduction}

32

Rainfall is one of the most important hydrological parameters that requires to be studied scrupulously, both in spatial and temporal scale. However, challenge comes in understanding the behavior of rainfall distribution pattern when applied on a regional scale. Pattern of rainfall, its frequency and magnitude may drastically vary depending upon the orography (Venkatesh and Jose 2007), large-scale synoptic and convective precipitation types (Karaca et al. 2000, Unal et al. 2012; Baltac1 et al. 2015; Efe et al. 2019) of the region. Scarcity of sufficient data at many sites of interest, may further complicate the investigation. To address this issue, the region may be classified into few homogeneous rainfall regions of similar rainfall distribution, also termed as regionalization. The Brahmaputra valley region is situated in the northeastern part of India, that has its own peculiar topography. The variations in the orographic arrangements and altitude differences in the region give rise to irregular and complex rainfall patterns at a local scale, which eventually amplifies the need of regionalization.

Regionalization has found its way into many applications in water resources planning, agricultural planning, drainage design, and estimating magnitude and frequency of extreme events like flood and drought. Literatures indicate that, in the past, political and geographical boundaries are used as a basis of forming homogeneous regions (Thomas and Benson 1970; NERC 1975; Beable and McKercher 1982; Chew et al. 1987). However, use of political and geographical boundaries is found to be not very convincing while forming hydrologically homogeneous regions (Bonell and Sumner 1992; Burn 1997; Rao and Srinivas 2006b; Satyanarayana and Srinivas 2011; Dikbas et al. 2012). A considerable amount of researches have been carried out in the recent years to identify homogeneous rainfall regions with various methods other than geographical divisions (Bedi and Bindra 1980; Bärring 1987; Sumner and Bonell 1988; Kulkarni et al. 1992; Gadgil et al. 1993; Burn 1997; Adelekan 1998). Regionalization with the use of principal component analysis (PCA) was found to be of use 
56 (Singh and Singh 1996; Wotling et al. 2000). When subjectivity involved with PCA came into

57 notice, the concept of cluster analysis started getting attention (Bonell and Sumner 1992;

Guttman 1993; Venkatesh and Jose 2007; Machiwal et al. 2019). Cluster analysis refers to a varied group of statistical procedures used to classify a multivariate dataset into some clusters or groups (Rao and Srinivas 2006a, b; Srinivas et al. 2008; Dikbas et al. 2012). Studies have also been done where PCA was further associated with various cluster analysis techniques for homogeneous clustering (Dinpashoh et al. 2004; Satyanarayana and Srinivas 2011; Darand and Daneshvar 2014; Machiwal et al. 2019). Ward's hierarchical cluster analysis is one of the widely used methods, that is found to be suitable for homogeneous regionalization (Unal et al. 2003; Baltac1 et al. 2017). Another vastly applied method is the k-means clustering (Rao and Srinivas 2006a; Pelczer et al. 2007; Agarwal et al. 2016). K-means clustering splits a region into hard clusters, i.e. with a degree of membership 1 or 0 . This means that a site can at most belong to only one cluster. However, this may not be valid in real world cases. To address this matter, the concept of fuzzy clustering was introduced to regionalization, which allows a site to fit into several clusters concurrently with a certain membership value. The fuzzy membership value of a site signifies the extent to which it fits into a particular group of sites (Rao and Srinivas 2006b). A lot of studies have successfully applied fuzzy clustering technique for clustering of hydrologically homogeneous regions in the recent years (Hall and Minns 1999; Owen et al. 2006; Plain et al. 2007; Sadri and Burn 2011; Satyanarayana and Srinivas 2011; Chen et al. 2011; Dikbas et al. 2012; Mok et al. 2012; Chavoshi et al. 2013; Asong et al. 2015; Bharath and Srinivas 2015; Goyal and Sharma 2016; Irwin et al. 2017; Wang et al. 2017). On the basis of critical reviews of earlier studies on regionalization, the aim of the current study is defined as to identify homogeneous rainfall regions in upper Brahmaputra Valley region of northeast India by using fuzzy clustering analysis. To achieve the best possible partition from 
81 Three different combinations of feature vectors were employed in FCM algorithm and the

82

83

84 outputs were compared for attaining best solutions to regionalization. The homogeneous rainfall regions (fuzzy clusters) thus formed by the use of FCM algorithm and validated with CVs were then assessed for statistical homogeneity by performing homogeneity tests using Lmoment approach (Hosking and Wallis 1997). The results were further compared with some previous regionalization studies and finally concluding remarks were presented.

\section{Methodology}

In the subsections below, the fuzzy c-means (FCM) algorithm for delineation of homogeneous clusters is described at first, which is followed by a brief description of the CVs, homogeneity test methods and process of adjustment of heterogeneous clusters. The methodology used is shown in Fig. 1, by means of a flow chart.

\subsection{Fuzzy C-Means clustering (FCM)}

The FCM approach is basically optimization of fuzzy c-means objective function. It was initially developed by Dunn (1973) and afterwards modified by Bezdek et al. (1984). The fuzzy c-means function to be minimized, is expressed as:

$$
J(\boldsymbol{Z} ; \boldsymbol{U}, \boldsymbol{V})=\sum_{i=1}^{c} \sum_{k=1}^{N}\left(\mu_{i k}\right)^{m}\left\|\mathbf{z}_{k}-\boldsymbol{v}_{i}\right\|^{2} A
$$

$\boldsymbol{U}=\left[\mu_{i k}\right] \in M_{f c}$ is the fuzzy partition matrix of $\boldsymbol{Z} ; \boldsymbol{V}=\left[\boldsymbol{v}_{1}, \boldsymbol{v}_{2}, \ldots, \boldsymbol{v}_{c}\right], \boldsymbol{v}_{i} \in R^{n}$ is vector of cluster centers to be determined; $d^{2}\left(\mathbf{z}_{k}, \boldsymbol{v}_{i}\right) A=D_{i k A}^{2}=\left\|\mathbf{z}_{k}-\boldsymbol{v}_{i}\right\|^{2} A=\left(\mathbf{z}_{k}-\boldsymbol{v}_{i}\right)^{T} A\left(\mathbf{z}_{k}-\boldsymbol{v}_{i}\right)$ is a squared distance norm; and $m$ is the fuzziness parameter or fuzzifier, where $m=[1, \infty)$. Usually, its value falls between 1 and 2.5 (Pal and Bezdek 1995).

\subsubsection{FCM algorithm for delineation of homogeneous rainfall regions}

(i) The initial fuzzy partition matrix $\boldsymbol{U}$ is set. 
105

106

107

108

109

110

111

113

114

115

116

117

118

119

120

121

122 The above steps from (iii) to (v) are repeated till the difference in the objective function for

123 two consecutive iterations becomes adequately small.

124

125

126

127

(ii) Then, initial membership values $\mu_{k i}^{i n i t}$ of $x_{i}$ that belongs to cluster $k$, is adjusted by using equation:

(iii) Fuzzy cluster centroid $\boldsymbol{v}_{k}$ is then calculated as

$$
\mu_{k i}=\frac{\mu_{k i}^{i n i t}}{\sum_{j=1}^{c} \mu_{j i}^{i n i t}}, \text { for } 1 \leq k \leq c, 1 \leq i \leq N
$$

(iv) Fuzzy membership value $\mu_{k i}$ is updated as

$$
\mathbf{v}_{\mathrm{k}}=\frac{\sum_{\mathrm{i}=1}^{\mathrm{N}}\left(\mu_{\mathrm{ki}}\right)^{\mathrm{m}} \mathbf{x}_{\mathrm{i}}}{\sum_{\mathrm{i}=1}^{\mathrm{N}}\left(\mu_{\mathrm{ki}}\right)^{\mathrm{m}}}, \text { for } 1 \leq \mathrm{k} \leq \mathrm{c}
$$

(v) The objective function is then calculated as

$$
\mu_{k i}=\frac{\left(\frac{1}{d^{2}\left(x_{i} v_{k}\right)}\right)^{\frac{1}{m-1}}}{\sum_{k=1}^{c}\left(\frac{1}{d^{2}\left(x_{i} v_{k}\right)}\right)^{\frac{1}{m-1}}}, \text { for } 1 \leq k \leq c, 1 \leq i \leq N
$$

$$
J(\boldsymbol{X} ; \boldsymbol{U}, \boldsymbol{V})=\sum_{k=1}^{c} \sum_{i=1}^{N}\left(\mu_{k i}\right)^{m} d^{2}\left(\boldsymbol{x}_{i}, \boldsymbol{v}_{k}\right)
$$

\subsection{Cluster validity indices (CVs)}

FCM algorithm divides the data into well separated and compact clusters, provided the optimal values of $c$ and $m$. Hence deciding the optimal values of these parameters is very crucial. Bezdek (1981) addressed this matter by stating the concept of validity indices. These indices 
essentially measure the goodness of the partitioned clusters. In hydrological studies several indices are used (Hall and Minns 1999; Srinivas et al. 2008). In case of FCM algorithm, the following CVs are found to perform well:

1. Fuzzy partition coefficient $\left(V_{P C}\right)$

$$
V_{P C}(U)=\frac{1}{N} \sum_{k=1}^{c} \sum_{i=1}^{N}\left(\mu_{k i}\right)^{2}
$$

2. Fuzzy partition entropy $\left(V_{P E}\right)$

$$
V_{P E}(U)=-\frac{1}{N}\left[\sum_{k=1}^{c} \sum_{i=1}^{N} \mu_{k i} \log \left(\mu_{k i}\right)\right]
$$

3. Fuzziness performance index $\left(V_{F P I}\right)$

$$
V_{F P I}(U)=1-\frac{c \times V_{P C}(U)-1}{c-1}
$$

4. Normalized classification entropy $\left(V_{N C E}\right)$

$$
V_{N C E}(U)=\frac{V_{P E}(U)}{\log (c)}
$$

Bezdek (1974a, b) formulated $V_{P C}$ and $V_{P E}$, whereas $V_{F P I}$ and $V_{\text {NCE }}$ were proposed by Roubens (1982). The range for $V_{P C}$ is $[1 / \mathrm{c}, 1] ; V_{P C}=1 / \mathrm{c}$ indicates equal sharing of clusters i.e. equal membership values of a data in all clusters (i.e. $\mu_{k i}=1 / \mathrm{c} \forall \mathrm{i}, \mathrm{k}$ ) and $V_{P C}=1$ indicates no sharing of membership among the clusters. Similarly, the range of $V_{P E}$ is $[0, \log (c)] . V_{P E}=0$ implies no sharing of membership among clusters and $\mathrm{V}_{\mathrm{PE}}=\log (\mathrm{c})$ implies equal sharing of clusters (i.e. $\left.\mu_{k i}=1 / \mathrm{c} \forall \mathrm{i}, \mathrm{k}\right)$. On the contrary, this range is $[0,1]$ for $\mathrm{V}_{\mathrm{FPI}}$ and $\mathrm{V}_{\mathrm{NCE}} ; 0$ implies no membership sharing between clusters and 1 implies equal sharing of clusters (i.e. $\mu_{k i}=1 / \mathrm{c} \forall \mathrm{i}, \mathrm{k}$ ). As such, a maximum value for $V_{P C}$ indicates optimum partition (i.e. minimum value for $V_{P E}, V_{F P I}$ and $\left.V_{N C E}\right)$, that means least overlap among clusters.

Earlier studies have stated that these four CVs tend to display monotonus increasing or decreasing trend (Rao and Srinivas 2006b, Srinivas et al., 2008). Hence, they are not very effective in obtaining optimum partition to delineate rainfall regions. Xie and Beni (1991) found no direct correlation of VPC and VPE with any property of the data. Furthermore, they are 
found to be very sensitive to the fuzzifier value, $m$ (Halkidi et al. 2001). Here, these indices are used mainly to validate their performances in detecting optimum cluster number. To eliminate this drawback the other validity indices are introduced, as explained below:

5. Extended Xie and beni index $\left(V_{X B}\right)$

$$
V_{X B, m}(U, V: X)=\frac{\sum_{k=1}^{c} \sum_{i=1}^{N}\left(\mu_{k i}\right)^{m} \mid x_{i}-v_{k} \|^{2}}{N \min _{l, l \neq k}\left\|v_{l}-v_{k}\right\|^{2}}
$$

Xie and Beni (1991) proposed the cluster validity index $\mathrm{V}_{\mathrm{XB}, \mathrm{m}}$. It quantifies the ratio of compactness within a fuzzy cluster to separation of clusters. Optimal partition of clusters should exhibit minimum value of $\mathrm{V}_{\mathrm{XB}, \mathrm{m}}$.

6. Fukuyama and Sugeno index $\left(V_{F S}\right)$

$$
V_{F S}(U, V: X)=\sum_{i=1}^{N} \sum_{k=1}^{c}\left(\mu_{k i}\right)^{m}\left\|\boldsymbol{x}_{i}-\boldsymbol{v}_{k}\right\|^{2} A-\sum_{i=1}^{N} \sum_{k=1}^{c}\left(\mu_{k i}\right)^{m}\left\|\boldsymbol{v}_{i}-\overline{\boldsymbol{v}}\right\|^{2} A
$$

Proposed by Fukuyama and Sugeno (1989), optimum partition is indicated by a minimum value of VFs.

\section{Kwon index $\left(V_{K}\right)$}

$$
V_{K}(U, V: X)=\frac{\sum_{k=1}^{c} \sum_{i=1}^{N}\left(\mu_{k i}\right)^{m_{\|}}\left\|x_{i}-v_{k}\right\|^{2}+\frac{1}{c} \sum_{k=1}^{c}\left\|\boldsymbol{v}_{i}-\bar{v}\right\|^{2}}{\min _{i \neq k}\left\|\boldsymbol{x}_{i}-\boldsymbol{v}_{k}\right\|^{2}}
$$

The Extended Xie and beni index $\left(V_{X B}\right)$ exhibits monotonous decreasing tendency as $\mathrm{c} \rightarrow \mathrm{N}$. To address this problem Kwon (1998) proposed another index $V_{K}$ that has an ad-hoc punishing function in numerator.

To determine the optimal values of $c$ and $m$, a range of values for the two parameters are selected and subsequent partitioning results show different sets of clusters, along with their validity indices. To decide the optimal set of values for $c$ and $m$ among those sets, first the optimum selection criteria of each of the validity indices are examined. Then, the sites having greater membership value in the clusters are identified, based on a threshold value of fuzzy membership $\left(T_{i}\right)$. Thus, a fuzzy cluster is made by allocating those sites to the cluster, whose membership values are found to be higher than or equal to the threshold fuzzy membership 
value $\left(T_{i}\right)$. The selection of this threshold value is subjective (Satyanarayana and Srinivas

177

2011). The most reasonable explanation would be to allocate the site to that group where its membership value is the highest. Yet, uncertainty arises when a site has low membership value in all the clusters or has equal memberships. To address this issue homogeneity test is done which is followed by adjustment of heterogeneous clusters. The methodologies for both of these are explained in the following subsection.

\subsection{Homogeneity test and adjustment of heterogeneous clusters}

The fuzzy clusters thus formed by using FCM algorithm and validated with CVs are then required to be assessed for statistical homogeneity by performing homogeneity tests. Heterogeneity measure (L-moment based) proposed by Hosking and Wallis performs better when skewness is low (average L-skew $<0.23$ ) for a sample set of data, whilst for higher skewness bootstrap Anderson-Darling test is recommended (Viglione et al. 2007). Previous studies have shown that Hosking and Wallis's homogeneity test is appropriate for delineation of homogeneous rainfall regions (Satyanarayana and Srinivas 2011), hence is considered in this study.

\subsubsection{L-moment of data samples}

L-moment is a method of explaining the probability distribution shape and evaluating the distribution parameters, especially for small sample sizes of environmental data, since it is unbiased and has a nearly normal distribution (Hosking 1990). Like usual moments, Lmoments too determines the location, dispersion, peakedness, skewness and any other feature of shape of probability distribution. However, L-moments are derived from linear combination of data (Hosking 1990). These statistics are established by modifying "probability weighted moments" (Greenwood et al. 1979), which explains L-moments by means of linear combinations. Sample probability weighted moments as explained by Greenwood et al. (1979) is given below: 
202

$$
b_{r}=n^{-1} \sum_{j=r+1}^{n} \frac{(j-1)(j-2) \ldots(j-r)}{(n-1)(n-2) \ldots(n-r)} x_{j}
$$

203

204

205

206

207

208

209

210

211

212

213

214

215

216

217

218

219

220

221

222

The first few L-moments and L-moment ratios are defined as:

$$
\text { Location, mean }\left(l_{1}\right): l_{1}=b_{0}
$$

\subsubsection{Discordancy measures, heterogeneity measures and adjustment of heterogeneous}

\section{clusters}

\section{Discordancy measures}

Discordancy measure $\left(D_{i}\right)$ detects those sites which are unacceptably discordant with the designated cluster (Hosking and Wallis 1993). This discordancy value for $\mathrm{i}^{\text {th }}$ site (Hosking and Wallis 1995) is given as,

$$
D_{i}=\frac{N}{3(N-1)}\left(u_{i}-\bar{u}\right)^{T} S^{-1}\left(u_{i}-\bar{u}\right)
$$

Here, $S$ is the sample covariance matrix expressed as:

$$
S=(N-1)^{-1} \sum_{i=1}^{N}\left(u_{i}-\bar{u}\right)\left(u_{i}-\bar{u}\right)^{T}
$$

where $u_{i}=\left[t^{(i)} t_{3}{ }^{(i)} t_{4}{ }^{(i)}\right]^{T}$ means a vector comprising of the values of $t, t_{3}$ and $t_{4}$ for $\mathrm{i}^{\text {th }}$ site.

Hence,

$$
\bar{u}=N^{-1} \sum_{i=1}^{N} u_{i}
$$

Large values of $D_{i}$ indicate probable errors in the site data. Hosking and Wallis (1993) explained that a particular site is not considered to be homogeneous with the region if $D_{i}$ is more than a certain critical value, than that. $D_{i} \geq 3$ is suggested as the criterion for affirming a site to be discordant, for regions with 15 or more sites. However, Hosking and Wallis (1993, 
223 1995) have advised to scrutinize the dataset for the largest $D_{i}$ values, irrespective of their 224 magnitude.

2. Heterogeneity measures

226 Heterogeneity measures give the degree of heterogeneity existing within the region. It is 227 estimated based on the extent of actual variability in L-moment ratios in relation to the expected variability in a homogeneous region. The heterogeneity measures to be estimated are $H_{1}, H_{2}$ and $H_{3}$. These measures are defined based on L-Cv, L-Skewness and L-Kurtosis. These three heterogeneity measures are given below.

i. Heterogeneity measures based on $\mathrm{L}-\mathrm{CV}$

ii. Heterogeneity measures based on L-Cv and L-Skewness

$$
H_{1}=\frac{V-\mu_{V}}{\sigma_{V}}
$$

iii. Heterogeneity measures based on L-Cv and L-Kurtosis

$$
H_{3}=\frac{V_{3}-\mu_{V 3}}{\sigma_{V 3}}
$$

Here $V$ is the weighted standard deviation or dispersion of the sample coefficients of Lvariation (L-Cv); $V_{2}$ and $V_{3}$ denote weighted average distance from the site to group weighted mean in a 2-D space of L-Cv/L-Skewness and L-Skewness/L-Kurtosis, respectively; $\mu_{V}, \mu_{V 2}$ and $\mu_{V 3}$ are the mean of $V, V_{2}$ and $V_{3}$ values, respectively, calculated from a large number of simulations $\left(N_{s i m}\right) ; \sigma V, \sigma V 2$ and $\sigma V 3$ are standard deviations of $V, V_{2}$ and $V_{3}$, respectively, calculated from a number of simulations. In this study $N_{\text {sim }}$ is takes as 1000 , simulated from kappa distribution and fitted using regional average L-moment ratios.

$$
\begin{aligned}
& V=\left\{\frac{\sum_{i=1}^{N} n_{i}\left(t^{(i)}-t^{(R)}\right)^{2}}{\sum_{i=1}^{N} n_{i}}\right\}^{1 / 2} \\
& V_{2}=\frac{\sum_{i=1}^{N} n_{i}\left\{\left(t^{(i)}-t^{(R)}\right)^{2}+\left(t_{3}^{(i)}-t_{3}^{(R)}\right)^{2}\right\}^{1 / 2}}{\sum_{i=1}^{N} n_{i}}
\end{aligned}
$$




$$
V_{3}=\frac{\sum_{i=1}^{N} n_{i}\left\{\left(t_{3}^{(i)}-t_{3}^{(R)}\right)^{2}+\left(t_{4}^{(i)}-t_{4}^{(R)}\right)^{2}\right\}^{1 / 2}}{\sum_{i=1}^{N} n_{i}}
$$

247 Here $N$ indicates number of sites/stations in the clustered region; $n_{i}$ indicates record length of 248 site $\mathrm{i} ; t^{(i)}, t_{3}^{(i)}$ and $t_{4}^{(i)}$ indicate sample L-moment ratios of site $\mathrm{i} ; t^{(R)}, t^{(R)}$ and $t 4^{(R)}$ indicate regional average L-moment ratios (L-Cv, L-Skewness and L-Kurtosis respectively). If $\mathrm{H}<1$ for a region, it is described as 'acceptably homogeneous', $1 \leq \mathrm{H}<2$ implies 'possibly heterogeneous', and $\mathrm{H} \geq 2$ implies 'definitely heterogeneous'. For further details on heterogeneity measures, Hosking and Wallis (1997) can be referred.

3. Adjustment of heterogeneous clusters

Clusters formed by the use of clustering algorithms does not always exhibit statistical homogeneity. Even after performing homogeneity test, there is a need to adjust the possibly or definitely heterogeneous clusters to come to a definite conclusion. Furthermore, it is assumed that there is not any cross-correlation among the data. Nevertheless, in actual scenarios there is gradual variation of rainfall across space, which implies that there exists cross-correlation among geographically contiguous sites (Satyanarayana and Srinivas 2011). So further adjustments are essential to form homogeneous regions. Studies suggest that, to decrease heterogeneity measures values, the discordant sites of one region can be either removed or shifted to some other region, after confirming that the site has not exhibited high fuzzy membership value in that cluster and discordancy of that site is not because of sampling variability (Rao and Srinivas 2006b; Satyanarayana and Srinivas 2011). The heterogeneous regions can also be broken into two or more regions, and if required two or more small regions can be merged together.

\section{Results and discussion}

\subsection{Geographic and climate properties of the study area}

Fig. 2 shows the study area, that is situated in the upstream part of Brahmaputra River in the state of Assam, covering the central Brahmaputra valley and the eastern Brahmaputra valley 
region. It covers most of the upper and middle Assam districts. This region of the valley is surrounded by Eastern Himalayas towards the north, the Patkai Bum in the east, the Naga Hills in the southern side and Meghalaya plateau in the far south. The Brahmaputra valley has a great geographical as well as political significance. It is surrounded by Bhutan in the north, Arunachal Pradesh in the north and east, Nagaland and Karbi-Anglong hills in the south. The study area lies between $25.921^{\circ} \mathrm{N}$ and $27.619^{\circ} \mathrm{N}$ latitudes and $91.896^{\circ} \mathrm{E}$ and $95.768^{\circ} \mathrm{E}$ longitudes. Mean annual precipitation varies from $859 \mathrm{~mm}$ to $3412 \mathrm{~mm}$ and the elevation varies from $67 \mathrm{~m}$ to $427 \mathrm{~m}$. Seasonal precipitation is found to be the highest in June-July-August (JJA) (406 mm - $1880 \mathrm{~mm})$ and the lowest in December-January-February (DJF) (9 mm - 222 $\mathrm{mm})$. The Brahmaputra valley has a subtropical climate which is influenced by northeast and southwest monsoon. The Meghalaya plateau, the Himalayas and the surrounding hills of Arunachal Pradesh, Manipur, Nagaland and Mizoram influences the climate. The monsoon winds coming from Bay of Bengal move towards the northeast and hits these mountains causing heavy precipitation on the valley.

\subsection{Data used}

A total of 83 raingauge stations with observed periods of varying number of years (from 5 years daily data to as long as 84 years and up to year 2016) were selected from various tea gardens of Assam. The location (longitude and latitude), seasonal precipitation (in mm), mean annual precipitation (in $\mathrm{mm}$ ) and elevation (in $\mathrm{m}$ ) of the raingauge stations are shown in the

Table 1. Elevation of each station was determined from Shuttle Radar Topography Mission's digital elevation model data (DEM) version 2.1 (SRTM-1) of 30m resolution. The DEM files come in tiles, that come as zipped SRTMHGT files at 1 -arcsecond resolution $(3601 \times 3601$ pixels) in a latitude/longitude projection (EPSG:4326). 
Previous studies suggest that, the attributes to be considered in clustering of homogeneous rainfall regions may include large scale atmospheric variables (LSAVs) of Global Climate Models (GCMs) or else principal components (PCs) of GCMs, location parameters (latitude, longitude, elevation etc.), and seasonality measures (maximum, minimum, standard deviation of rainfall etc.). In the present study, total annual rainfall, total monthly rainfall, standard deviation of total annual rainfall and total monthly rainfall and all three location parameters i.e. latitude, longitude and elevation of all the 83 raingauge stations were included as attributes. Here three different combinations of feature vectors were used to form, consequently, three different sets of input data matrices (for FCM algorithm). This was done in order to observe the effect of a particular attribute in the cluster formation. The three combinations were as follows:

Case 1: Input data matrix with total monthly rainfall as attributes,

Case 2: Input data matrix with standard deviation of total monthly rainfall as attributes,

Case 3: Input data matrix with latitude, longitude, elevation, total annual rainfall and standard deviation of total annual rainfall as attributes.

To acquire reliable results from clustering, most crucial point is to assume the cluster number (c), since the number of regions is unknown beforehand. The best way to do that is to choose a range of values for $c$, and then to find out the most appropriate one. To achieve that, the cluster number $c$ is changed from 2 to $k$, k being a quantity lesser than total number of sites, $N$. The lower bound of $c$ is taken as 2 , because the dataset is apparently clustered into more than one group. The interesting point here is to define the upper bound of $c$, i.e. the parameter $k$. Varying the $k$ value impacts the reliability of cluster number. From research, it was noticed that increasing the $k$ value generates more consistent cluster number division (Mok et al 2012). Many works can be found in literature on identification of optimal cluster numbers. In most of the cases, $k \leq N^{1 / 2}$ is suggested as the upper bound (Xie and Beni 1991; Pal and Bezdek 1995; 
Mok et al 2012). In a similar way, optimum value of fuzzifier $(m)$ also needs to be found out.

Pal and Bezdek (1995) presented that FCM algorithm works well when $m$ varies from 1-2.5.

It is hence suggested (Satyanarayana and Srinivas 2011) to attain a number of sets of clustered regions by selecting a range of values for $c$ and $m$, and then identify the final clustered regions based on the optimal values of $c$ and $m$ and by means of CVs.

In this study, FCM algorithm was executed for each case with cluster number varying from $c_{\text {min }}=2$ to $c_{\max }$ or $(k)=(83)^{1 / 2} \approx 10$, with increment 1 . The fuzzifier value $(m)$ is increased from of fuzzifier $m$ were plotted for cluster number varying from 2 to 10 , for all the three cases and are shown in Fig. 3a, 3b and 3c. It is observed that, as the fuzzifier value increases the optimum value of objective function declines, for a given cluster number. In a similar way, the optimum value decreases with rise in cluster number, for a given value of fuzzifier. The FCM algorithm was found to perform better for $m$ in the range of 1.5-2.5.

Further, the CVs described in section 2.2, were calculated to achieve the optimal value of $c$ and $m$, for each case. The values of $V_{P C}, V_{P E}, V_{F P I}, V_{N C E}, V_{X B}, V_{F S}$, and $V_{K}$ are tabulated in supplementary material. Since the FCM algorithm performed better for $m$ in the range of 1.52.5, the CVs for higher value of $m$ are not considered and hence are not shown in the tables. In all the three cases, it is observed that, $V_{P C}$ decreases monotonously whereas $V_{P E}, V_{F P I}$ and $V_{N C E}$ show increase monotonously with increase in the fuzzifier value, $m$, for a given value of cluster number $c$. Moreover, they show overall monotonous decreasing $\left(V_{P C}\right)$ and increasing $\left(V_{P E}, V_{F P I}\right.$ and $V_{N C E}$ ) tendency with increase in the cluster number $c$, hence giving always low value of $c$ and $m$ as the optimum set of values for homogeneous clustering. This indicates their ineffectiveness in determining optimum number of homogeneous rainfall regions. effective in these cases. They didn't show any monotonous increasing or decreasing tendency 
with change in the values of $c$ and $m$, and were in line with each other. In case of Fukuyama and Sugeno index $\left(V_{F S}\right)$, although it didn't have any monotonic tendency, the values were found to be in a conflict to the values of $V_{X B}$, and $V_{K}$ in some cases. Taking into account of the similar studies on homogeneous rainfall region identification, found in literature (Rao and Srinivas 2006b; Satyanarayana and Srinivas 2011; Farsadnia et al. 2014; etc.), $V_{X B}$ and $V_{K}$ were opted for clustering of rainfall regions. Henceforth, the clusters found from these two indices were considered for further analysis. The optimal value of clusters $c=3$ was identified for all the three cases, using these CVs with the corresponding value of $m=1.5$ for all three cases.

\subsection{Homogeneity test and adjustment of heterogeneous clusters}

The $\mathrm{H}$ values of homogeneity test for all the three cases are given in Table 2. Initially, out of the nine clusters (three clusters for each case), four clusters were acceptably homogeneous, four clusters were possibly heterogeneous and one cluster was definitely heterogeneous. Hence, adjustments were done to make the possibly and definitely heterogeneous clusters as homogeneous, by either shifting discordant sites from one cluster to another or by removing those sites if necessary. For case 1, stations Chubwa and Dilli were found to discordant with all the clusters; hence they are removed during adjustment which lead to three acceptably homogeneous clusters with the rest 81 stations. Similarly, station Chubwa was found to be discordant for case 2; hence removed from the clusters and adjustments were done for 82 stations. However, in case 3, no stations were removed. The reason that the two stations did not show any discordancy in case 3 is because the geographic locations of the stations were considered during cluster analysis for case 3 . The $\mathrm{H}$ values of homogeneity test after adjustment and number of sites in each cluster are shown in Table 2. Final clusters formed after adjustment are shown in Fig. 4a, 4b and 4c. 
369 Although this is the first and foremost study to divide the Brahmaputra valley region of India into hydrologically homogeneous regions with the use of rainfall data record by the tea gardens by applying fuzzy clustering technique and seven cluster validity indices (CVs), few previous studies can be found on use of various clustering techniques for Indian subcontinent. Hence, comparisons have been made with those closely related studies to validate the performance of the present study. The homogeneous regions developed by Indian Meteorological Department (IMD) displays five large provinces, which are although delineated based on rainfall characteristics but are influenced by contiguity of area and administrative state boundaries. Iyengar and Basak (1994) used principal component analysis (PCA) for regionalization of Indian monsoon rainfall and recommended the PCA approach for further subdivision of the region. Ten homogeneous sequential regions were formed in India from their analysis, in which the stations of upper Brahmaputra valley regions were seemed to form similar kind of clusters as found in the present study, although few stations remained un-clustered. Singh and Singh (1996) have done regionalization of monthly as well as seasonal rainfall for sub-Himalayan areas and Gangetic plains, by using principal component analysis (PCA). They used rainfall data for a period of 114 years (1871-1984) from 90 well distributed stations which resulted into four distinct homogeneous rainfall areas for both monthly and seasonal scales. Srinivasa and Kumar (2007) utilized fuzzy cluster analysis (FCA) to classify 159 meteorological stations in India and concluded that FCA method performs well than the Kohonen Artificial Neural Networks (KANN) method in finding meteorologically homogeneous groups. They utilized location parameters (latitude, longitude and elevation) along with other meteorological parameters for clustering and the results exhibited 14 clusters over Indian region, the Northeastern region being in one cluster. Satyanarayana and Srinivas (2008) have done regional frequency analysis using LSAVs that affects the precipitation in a region instead of observed precipitation data and have used K-means clustering with adjustments and L-statistics for 
regionalization. 17 homogeneous regions were formed after the analysis, two regions covering the northeastern states. The upper Brahmaputra valley region came under the same homogeneous cluster, hence producing similar results to those of the present study. Satyanarayana and Srinivas (2011) have done regionalization of rainfall data, based on fuzzy clustering method by utilizing GCM data, location parameters and seasonal precipitation data.

The stations of upper Brahmaputra valley regions were seemed to form similar kind of clusters as found in the present study. Stations in middle Assam were found to form one cluster while other stations on the upper Assam formed a different cluster. Saikranthi et al. (2013) used correlation analysis for regionalization based on seasonal and annual rainfall data. They used 51 years (1951-2001) daily rainfall data collected for more than 1000 rain gauges across India for the analysis, which produced 26 homogeneous rainfall zones. However, because of data scarcity northeastern states were not included in the analysis. Bharath and Srinivas (2015) used wavelet-based global FCM analysis, instead of PCA for determining homogeneous hydrometeorological regions in India. The new approach proposed by them clustered the Indian territory into 29 regions, northeastern region having 7 clusters. The clusters formed in the upper Brahmaputra valley region were similar to the present study. Kulkarni (2017) has used probability density function to divide the Indian subcontinent into homogeneous clusters, using daily summer monsoon rainfall at 357 square grids of size $10000 \mathrm{sqkm}$. The study produced five clusters, out of which one cluster covered adjoining regions and all other clusters were scattered indicating irregular behaviour of daily rainfall pattern in India. The study was done by using two time periods 1901-1975 and 1976-2010, and the resulting clusters were found to be extremely different in the two time periods. The clusters formed in the northeastern region is also different for the two periods which are not entirely in line with the present study.

417 However, they used gridded rainfall data instead of station data, thus the difference. Mannan 418 et al. (2018) have used climatic variables and self-organizing maps to regionalize India. 
419 Artificial neural network is used along with four CVs for clustering and applied on gridded rainfall dataset $\left(0.25^{\circ} \times 0.25^{\circ}\right)$ from IMD for 34 years $(1980-2013)$ as well as climatic variables such as air temperature, surface pressure, geo-potential height, specific humidity, etc. 10 homogeneous regions were formed when only rainfall data was used, whereas incorporation of climatic variables divided the region into 15 regions. The region 2 in their study covered the northeast India with rainfall of $7.2 \mathrm{~mm} / \mathrm{day}$.

\section{Conclusion}

In this paper, fuzzy clustering approach has been used to classify regions with homogeneous rainfall in upper Brahmaputra Valley region of northeast India. Three different combinations of feature vectors were employed in FCM algorithm to attain the best solutions to regionalization. Seven different CVs were used to determine the optimal partition in the fuzzy c-means (FCM) algorithm, out of which Extended Xie and beni index $\left(V_{X B}\right)$ and Kwon index $\left(V_{K}\right)$ were opted for clustering of rainfall regions owing to their satisfactory performance. The optimal value of cluster number for all three cases was identified as $c=3$, with corresponding value of $m=1.5$. The clustered regions were then assessed for statistical homogeneity by performing homogeneity tests using L-moment approach. Four clusters were found to be acceptably homogeneous. Other possibly heterogeneous and definitely heterogeneous clusters were made homogenous by adjusting the discordant sites. It was found from the results that the clustering pattern was improved in case 3, where geographical location parameters (latitude, longitude and elevation) were included along with local rainfall data of tea gardens. It indicates that if regionalization needs to be done at a local scale such as an average sized watershed, further sub-clustering of a clustered region may be required. Local rainfall data, along with geographical location parameter details, can be used for the purpose since GCM data will not

442 be of much use in this aspect because of their coarse resolution. However, a good rainfall 443 dataset with large number of station points is required to be available within the region. 
445 Authors acknowledge the teagarden authorities for making the data available. Our deepest 446 gratitude is extended to the editors and anonymous reviewers for their valuable comments and

447 suggestions.

\section{Author's Contribution}

449 Conceptualization: Jayshree Hazarika, Arup Kumar Sarma; methodology: Jayshree Hazarika, 450 Arup Kumar Sarma; formal analysis and investigation: Jayshree Hazarika; writing - original 451 draft preparation: Jayshree Hazarika; writing - review and editing: Arup Kumar Sarma; 452 resources: Arup Kumar Sarma; supervision: Arup Kumar Sarma.

\section{$453 \quad$ Funding}

454 This research did not receive any specific grant from funding agencies in the public, 455 commercial, or not-for-profit sectors.

\section{Availability of data and material}

457 All relevant data are provided in both main manuscript and supplementary material.

\section{Code availability}

459 Not applicable

\section{Declaration}

461 Ethics approval All procedures performed in this study were in accordance with the ethical 462 standards of the institution or any comparable ethical standards.

463 Consent to participate We (authors) are agreed that Jayshree Hazarika planned, performed 464 the analysis, and wrote the paper, while Arup Kumar Sarma provided the resources and added 465 his expertise in the analysed results.

466 Consent for publication We give consent for our paper to be published in your Theoretical 467 and Applied Climatology journal. 
468 Conflict of interest The authors have no conflicts of interest to declare that are relevant to the 469 content of this article.

\section{$470 \quad$ References}

471 Adelekan IO (1998) Spatio-temporal variations in thunderstorm rainfall over Nigeria. 472 International Journal of Climatology 18:1273-1284. https://doi.org/10.1002/(SICI)10970088(199809)18:11<1273::AID-JOC298>3.0.CO;2-4

474 Agarwal A, Maheswaran R, Sehgal V, Khosa R, Sivakumar B, Bernhofer C (2016) Hydrologic regionalization using wavelet-based multiscale entropy method. Journal of Hydrology 538:2232. https://doi.org/10.1016/j.jhydrol.2016.03.023

Asong ZE, Khaliq MN, Wheater HS (2015) Regionalization of precipitation characteristics in the Canadian Prairie Provinces using large-scale atmospheric covariates and geophysical attributes. Stochastic Environmental Research and Risk Assessment 29:875-892. https://doi.org/10.1007/s00477-014-0918-z

Baltacı H, Göktürk OM, Kındap T, Ünal A, Karaca M (2015) Atmospheric circulation types in Marmara Region (NW Turkey) and their influence on precipitation. International Journal of Climatology 35:1810-1820. https://doi.org/10.1002/joc.4122

Baltacı H, Kındap T, Ünal A, Karaca M (2017) The influence of atmospheric circulation types on regional patterns of precipitation in Marmara (NW Turkey). Theoretical and Applied Climatology 127:563-572. https://doi.org/10.1007/s00704-015-1653-1

487 Bärring L (1987) Spatial patterns of daily rainfall in central Kenya: application of principal 488 component analysis and spatial correlation. Journal of Climatology 7(3):267-290. https://doi.org/10.1002/joc.3370070306 
492

493

494

495

496

497

498

499

500

501

502

503

504

505

506

507

508

509

510

511

512

513

514

Bedi HS, Bindra MMS (1980) Principal components of monsoon rainfall. Tellus 32(3):296298. https://doi.org/10.3402/tellusa.v32i3.10584

Bezdek JC (1974a) Numerical taxonomy with fuzzy sets. Journal of Mathematical Biology 1(1):57-71. https://doi.org/10.1007/BF02339490

Bezdek JC (1974b) Cluster validity with fuzzy sets. Journal of Cybernetics 3(3):58-73. https://doi.org/10.1080/01969727308546047

Bezdek JC (1981) Pattern recognition with fuzzy objective function algorithms. Plenum Press, New York. https://doi.org/10.1007/978-1-4757-0450-1

Bezdek JC, Ehrlich R, Full W (1984) FCM: the fuzzy c-means clustering algorithm. Computers \& Geosciences 10:191-203. https://doi.org/10.1016/0098-3004(84)90020-7

Bharath R, Srinivas VV (2015) Delineation of homogeneous hydrometeorological regions using wavelet-based global fuzzy cluster analysis. International Journal of Climatology 35: 4707-4727. https://doi.org/10.1002/joc.4318

Bonell M, Sumner G (1992) Atmospheric circulation and daily precipitation in Wales. Theoretical and Applied Climatology 46:3-25. https://doi.org/10.1007/BF00866443

Burn DH (1997) Catchment similarity for regional flood frequency analysis using seasonality measures. Journal of Hydrology 202:212-230. https://doi.org/10.1016/S0022-1694(97)000681

Chavoshi S, Azmin Sulaiman WN, Saghafian B, bin Sulaiman MN, Manaf LA (2013) Regionalization by fuzzy expert system based approach optimized by genetic algorithm. Journal of Hydrology 486:271-280. https://doi.org/10.1016/j.jhydrol.2013.01.033

Chen J, Zhao S, Wang H (2011) Risk Analysis of Flood Disaster Based on Fuzzy Clustering Method. Energy Procedia 5:1915-1919. https://doi.org/10.1016/j.egypro.2011.03.329 
515 Chew HH, Heiler M, David T (1987) Magnitude and frequency of floods in peninsular

516 malaysia (revised and updated) 1987, 1987th edn. Ministry of Agriculture and Fisheries,

517 Malayasia

518 Darand M, Daneshvar MRM (2014) Regionalization of precipitation regimes in Iran using 519 principal component analysis and hierarchical clustering analysis. Environmental Processes 1:517-532. https://doi.org/10.1007/s40710-014-0039-1

521 Dikbas F, Firat M, Koc AC, Gungor M (2012) Classification of precipitation series using fuzzy 522 cluster method. International Journal of Climatology 32:1596-1603. 523 https://doi.org/10.1002/joc.2350

524 Dinpashoh Y, Fakheri-Fard A, Moghaddam M, Jahanbakhsh S, Mirnia M (2004) Selection of variables for the purpose of regionalization of Iran's precipitation climate using multivariate methods. Journal of Hydrology 297:109-123. https://doi.org/10.1016/j.jhydrol.2004.04.009

527 Dunn JC (1973) A fuzzy relative of the ISODATA process and its use in detecting compact, well-separated clusters. Journa of Cybernetics $3(3): 32-57$. https://doi.org/10.1080/01969727308546046

530 Efe B, Lupo AR, Deniz A (2019) The relationship between atmospheric blocking and 531 precipitation changes in Turkey between 1977 and 2016. Theoretical and Applied Climatology 138:1573-1590. https://doi.org/10.1007/s00704-019-02902-z

533 Farsadnia F, Kamrood MR, Nia AM, Modarres R, Bray MT, Han D, Sadatinejad J (2014) 534 Identification of homogeneous regions for regionalization of watersheds by two-level self535 organizing feature maps. Journal of Hydrology 509:387-397. 536 https://doi.org/10.1016/j.jhydrol.2013.11.050

537 Fukuyama Y, Sugeno M (1989) A new method of choosing the number of clusters for the fuzzy 538 c-means method. Proceedings of Fifth Fuzzy Systems Symposium, pp. 247-250 (in Japanese). 
539 Gadgil S, Yadumani, Joshi NV (1993) Coherent rainfall zones of the Indian region. 540 International Journal of Climatology 13(5):547-566. https://doi.org/10.1002/joc.3370130506

541 Goyal MK, Sharma A (2016) A fuzzy c-means approach regionalization for analysis of 542 meteorological drought homogeneous regions in western India. Natural Hazards 84(3):1831543 1847. https://doi.org/10.1007/s11069-016-2520-9

544 Greenwood JA, Landwehr JM, Matalas NC, Wallis JR (1979) Probability weighted moments: definition and relation to parameters of several distributions expressible in inverse form. Water Resources Research 15(5):1049-1054. https://doi.org/10.1029/WR015i005p01049

547 Guttman NB (1993) The Use of L-Moments in the Determination of Regional Precipitation 548 Climates. Journal of Climate 6:2309-2325. https://doi.org/10.1175/15200442(1993)006<2309:TUOLMI>2.0.CO;2

Halkidi M, Batistakis Y, Vazirgiannis M (2001) On clustering validation techniques. Journal of Intelligent Information Systems 17:107-145. https://doi.org/10.1023/A:1012801612483 Hall MJ, Minns AW (1999) The classification of hydrologically homogeneous regions. Hydrological Sciences Journal 44(5):693-704. https://doi.org/10.1080/02626669909492268 Hosking JRM (1990) L-moments: Analysis and estimation of distributions using linear combinations of order statistics. Journal of the Royal Statistical Society: Series B (Methodological) banner 52(1):105-124. https://doi.org/10.1111/j.2517-6161.1990.tb01775.x Hosking JRM, Wallis JR (1993) Some Statistics useful in regional frequency analysis. Water Resources Research 29(2):271-281. https://doi.org/10.1029/92WR01980

559 Hosking JRM, Wallis JR (1995) Correction to "Some statistics useful in regional frequency 560 analysis". Water Resources Research 31(1):251. https://doi.org/10.1029/94WR02510

561 Hosking JRM, Wallis JR (1997) Regional frequency analysis: an approach based on L562 moments. Cambridge University $\quad$ Press, 563 https://doi.org/10.1017/CBO9780511529443 
564 Irwin S, Srivastav RK, Simonovic SP, Burn DH (2017) Delineation of precipitation regions

565 using location and atmospheric variables in two Canadian climate regions: the role of attribute

566

selection.

Hydrological

Sciences

Journal

62:191-204.

567 https://doi.org/10.1080/02626667.2016.1183776

568 Iyengar RN, Basak P (1994) Regionalization of Indian monsoon rainfall and long-term

569 variability signals. International Journal of Climatology 14:1095-1114.

570 https://doi.org/10.1002/joc.3370141003

571 Karaca M, Deniz A, Tayanc M (2000) Cyclone Track Variability Over Turkey in Association

572 with Regional Climate. International Journal of Climatology 20:1225-1236.

573 https://doi.org/10.1002/1097-0088(200008)20:10\%3C1225::AID-JOC535\%3E3.0.CO;2-1

574 Kulkarni A (2017) Homogeneous clusters over India using probability density function of daily

575 rainfall. Theoretical and Applied Climatology 129:633-643. https://doi.org/10.1007/s00704-

$576 \quad 016-1808-8$

577 Kulkarni A, Kripalani RH, Singh SV (1992) Classification of summer monsoon rainfall

578 patterns over India. International Journal of Climatology 12(3):269-280.

579 https://doi.org/10.1002/joc.3370120304

580 Kwon SH (1998) Cluster Validity Index for Fuzzy Clustering. Electronics Letters

581

34(22):2176-2177. https://doi.org/10.1049/el:19981523

582 Machiwal D, Kumar S, Meena HM, Santra P, Singh RK, Singh DV (2019) Clustering of

583 rainfall stations and distinguishing influential factors using PCA and HCA techniques over the

584 western dry region of India. Meteorological Applications 26:300-311.

585 https://doi.org/10.1002/met.1763

586 Mannan A, Chaudhary S, Dhanya CT, Swamy AK (2018) Regionalization of rainfall

587 characteristics in India incorporating climatic variables and using self-organizing maps. ISH 
Mok PY, Huang HQ, Kwok YL, Au JS (2012) A robust adaptive clustering analysis method

591 for automatic identification of clusters. Pattern Recognition 45:3017-3033.

592 https://doi.org/10.1016/j.patcog.2012.02.003

593

NERC (1975) Flood Studies Report, five volumes. Natural Environmental Research Council

(NERC), Department of the Environment, London

595

596

597

598

599

600

601

602

603

604

605

606

607

608

609

610

611

612

Owen SM, MacKenzie AR, Bunce RGH, Stewart HE, Donovan RG, Stark G, Hewitt CN (2006) Urban land classification and its uncertainties using principal component and cluster analyses: A case study for the UK West Midlands. Landscape and Urban Planning 78:311321. https://doi.org/10.1016/j.landurbplan.2005.11.002

Pal NR, Bezdek JC (1995) On cluster validity for the fuzzy c-means model. IEEE Transactions on Fuzzy Systems 3(3):370-379. https://doi.org/10.1109/91.413225

Pelczer I, Ramos J, Domínguez R, González F (2007) Establishment of regional homogeneous zones in a watershed using clustering algorithms. In: 32 Congress of IAHR Harmonizing the Demands of Art and Nature in Hydraulics, IAHR, Venice, Italy, File. http://citeseerx.ist.psu.edu/viewdoc/summary?doi=10.1.1.107.3470

Plain MB, Minasny B, McBratney AB, Vervoort RW (2008) Spatially explicit seasonal forecasting using fuzzy spatiotemporal clustering of long-term daily rainfall and temperature data. Hydrology and Earth System Sciences Discussions 5:1159-1189. https://doi.org/10.5194/hessd-5-1159-2008

Rao AR, Srinivas VV (2006a) Regionalization of watersheds by hybrid-cluster analysis. Journal of Hydrology 318:37-56. https://doi.org/10.1016/j.jhydrol.2005.06.003

Rao AR, Srinivas VV (2006b) Regionalization of watersheds by fuzzy cluster analysis. Journal of Hydrology 318:57-79. https://doi.org/10.1016/j.jhydrol.2005.06.004 
613 Roubens M (1982) Fuzzy clustering algorithms and their cluster validity. European Journal of

614 Operational Research 10:294-301. https://doi.org/10.1016/0377-2217(82)90228-4

615 Sadri S, Burn DH (2011) A Fuzzy C-Means approach for regionalization using a bivariate 616 homogeneity and discordancy approach. Journal of Hydrology 401:231-239. 617 https://doi.org/10.1016/j.jhydrol.2011.02.027

618 Saikranthi K, Rao TN, Rajeevan M, Bhaskara Rao SV (2013) Identification and Validation of 619 Homogeneous Rainfall Zones in India Using Correlation Analysis. Journal of 620 Hydrometeorology 14:304-317. https://doi.org/10.1175/JHM-D-12-071.1

621 Satyanarayana P, Srinivas VV (2008) Regional frequency analysis of precipitation using large622 scale atmospheric variables. Journal of Geophysical Research 113:1-16. 623 https://doi.org/10.1029/2008JD010412

624 Satyanarayana P, Srinivas VV (2011) Regionalization of precipitation in data sparse areas 625 using large scale atmospheric variables - A fuzzy clustering approach. Journal of Hydrology 626 405:462-473. https://doi.org/10.1016/j.jhydrol.2011.05.044

627 Singh KK, Singh SV (1996) Space-time variation and regionalization of seasonal and monthly 628 summer monsoon rainfall of the sub-Himalayan region and Gangetic plains of India. Climate 629 Research 6:251-262. https://doi.org/10.3354/cr006251

630 Srinivas VV, Tripathi S, Rao AR, Govindaraju RS (2008) Regional flood frequency analysis 631 by combining self-organizing feature map and fuzzy clustering. Journal of Hydrology 632 348:148-166. https://doi.org/10.1016/j.jhydrol.2007.09.046

633 Srinivasa RK, Nagesh KD (2007) Classification of Indian meteorological stations using cluster 634 and fuzzy cluster analysis, and Kohonen artificial neural networks. Nordic Hydrology 635 38(3):303-314. https://doi.org/10.2166/nh.2007.013 
636 Sumner G, Bonell M (1988) Variation in the spatial organisation of daily rainfall during the 637 north Queensland wet seasons, 1979-82. Theoretical and Applied Climatology 39:59-72.

638

639

640

641

642

643

644

645

646

647

648

649

650

651

652

653

654

655

656

657

658

659

660

https://doi.org/10.1007/BF00866390

Thomas DM, Benson M a (1970) Generalization of streamflow characteristics from drainagebasin characteristics. https://doi.org/10.3133/wsp1975

Unal Y, Kindap T, Karaca M (2003) Redefining the climate zones of Turkey using cluster analysis. International Journal of Climatology 23:1045-1055. https://doi.org/10.1002/joc.910

Unal YS, Deniz A, Toros H, Incecik S (2012) Temporal and spatial patterns of precipitation variability for annual, wet, and dry seasons in Turkey. International Journal of Climatology 32(3):392-405. https://doi.org/10.1002/joc.2274

Venkatesh B, Jose MK (2007) Identification of homogeneous rainfall regimes in parts of Western Ghats region of Karnataka. Journal of Earth System Science 116(4):321-329. https://doi.org/10.1007/s12040-007-0029-z

Viglione A, Laio F, Claps P (2007) A comparison of homogeneity tests for regional frequency analysis. Water Resources $\quad$ Research 43(W03428):1-10. https://doi.org/10.1029/2006WR005095

Wang Z, Zeng Z, Lai C, Lin W, Wu X, Chen X (2017) A regional frequency analysis of precipitation extremes in Mainland China with fuzzy c-means and L-moments approaches. International Journal of Climatology 37: 429-444. https://doi.org/10.1002/joc.5013

Wotling G, Bouvier C, Danloux J, Fritsch J-M (2000) Regionalization of extreme precipitation distribution using the principal components of the topographical environment. Journal of Hydrology 233:86-101. https://doi.org/10.1016/S0022-1694(00)00232-8

Xie XL, Beni G (1991) A validity measure for fuzzy clustering. IEEE Transactions on Pattern Analysis and Machine Intelligence 13(8):841-847. https://doi.org/10.1109/34.85677 
661 LIST OF TABLES

662 Table 1 Location details of raingauge stations located in various tea gardens of the upper

663 Brahmaputra valley region with mean annual and seasonal precipitation

664 Table 2 Results of homogeneity test

665 


\begin{tabular}{|c|c|c|c|c|c|c|c|c|c|}
\hline \multirow[t]{2}{*}{ SI. No. } & \multirow{2}{*}{$\begin{array}{c}\text { Name of the } \\
\text { station }\end{array}$} & \multirow{2}{*}{$\begin{array}{c}\text { Longitude } \\
\left({ }^{0} \mathrm{E}\right)\end{array}$} & \multirow{2}{*}{$\begin{array}{l}\text { Latitude } \\
\left({ }^{0} \mathbf{N}\right)\end{array}$} & \multicolumn{4}{|c|}{ Seasonal rainfall in $\mathrm{mm}$} & \multirow{2}{*}{$\begin{array}{l}\text { Total annual } \\
\text { rainfall in mm }\end{array}$} & \multirow{2}{*}{$\begin{array}{l}\text { Elevation } \\
\text { in } \mathbf{m}\end{array}$} \\
\hline & & & & DJF & MAM & JJA & SON & & \\
\hline 1 & Abhoijan & 93.8986111 & 26.4225 & 70 & 610 & 1127 & 510 & 2317 & 121 \\
\hline 2 & Achabam & 95.2644444 & 27.24 & 82 & 579 & 1249 & 401 & 2312 & 123 \\
\hline 3 & Amsoi & 92.4102778 & 26.1433333 & 31 & 326 & 843 & 346 & 1546 & 67 \\
\hline 4 & Anand & 94.2300797 & 27.4619764 & 101 & 525 & 1880 & 719 & 3225 & 112 \\
\hline 5 & Arin & 93.9752778 & 26.4877778 & 49 & 478 & 831 & 321 & 1679 & 100 \\
\hline 6 & Arun & 92.4402778 & 26.6669444 & 32 & 451 & 823 & 257 & 1563 & 80 \\
\hline 7 & Athabari & 94.0347222 & 26.4138889 & 9 & 301 & 525 & 162 & 996 & 104 \\
\hline 8 & Azizbagh & 95.1302778 & 27.2063889 & 111 & 698 & 1354 & 479 & 2642 & 113 \\
\hline 9 & Bahani & 94.2025 & 26.7555556 & 79 & 552 & 905 & 449 & 1985 & 93 \\
\hline 10 & Basmatia & 95.0671167 & 27.3605556 & 81 & 637 & 1126 & 409 & 2253 & 113 \\
\hline 11 & Bateli & 92.2537422 & 26.7759589 & 35 & 430 & 907 & 340 & 1712 & 112 \\
\hline 12 & Bhelaguri & 94.3846566 & 26.7048311 & 57 & 489 & 830 & 279 & 1654 & 116 \\
\hline 13 & Bokajan & 93.7751667 & 26.022 & 22 & 260 & 548 & 254 & 1084 & 136 \\
\hline 14 & Bokakhat & 93.6438889 & 26.6377778 & 58 & 553 & 975 & 382 & 1968 & 87 \\
\hline 15 & Borahi & 94.9902778 & 27.0433333 & 59 & 684 & 1291 & 454 & 2488 & 104 \\
\hline 16 & Borchapori & 93.6899 & 26.6381972 & 75 & 550 & 1143 & 406 & 2174 & 92 \\
\hline 17 & Borhat & 95.2888889 & 27.1388889 & 29 & 238 & 406 & 187 & 859 & 122 \\
\hline 18 & Borjan & 94.0577778 & 26.5619444 & 39 & 393 & 745 & 271 & 1448 & 104 \\
\hline 19 & Borpathar & 93.8488889 & 26.2722222 & 44 & 404 & 708 & 274 & 1430 & 127 \\
\hline 20 & Chubwa & 95.1730556 & 27.4661111 & 99 & 835 & 1447 & 601 & 2981 & 118 \\
\hline 21 & Cinnatolliah & 94.0857124 & 27.342037 & 110 & 653 & 1709 & 589 & 3061 & 123 \\
\hline 22 & Dalowjan & 93.9747222 & 26.4338889 & 54 & 425 & 729 & 347 & 1555 & 105 \\
\hline 23 & Deamoolie & 95.5388889 & 27.5905556 & 91 & 670 & 1275 & 442 & 2478 & 134 \\
\hline 24 & Dejoo & 94.0031433 & 27.2807217 & 106 & 661 & 1690 & 544 & 3002 & 123 \\
\hline 25 & Dekorai & 92.9636778 & 26.81 & 56 & 608 & 1238 & 445 & 2347 & 83 \\
\hline 26 & Deohall & 95.2890372 & 27.4223095 & 103 & 710 & 1152 & 379 & 2344 & 125 \\
\hline 27 & Dhekiajuli & 92.4615703 & 26.6904332 & 57 & 572 & 1090 & 391 & 2110 & 77 \\
\hline 28 & Dholaguri & 93.84161 & 26.5128231 & 49 & 479 & 822 & 272 & 1622 & 99 \\
\hline
\end{tabular}




\begin{tabular}{|c|c|c|c|c|c|c|c|c|c|}
\hline 29 & Digulturrung & 95.4119444 & 27.6104528 & 58 & 631 & 905 & 309 & 1903 & 126 \\
\hline 30 & Dilli & 95.3672222 & 27.1638889 & 118 & 732 & 1507 & 519 & 2877 & 132 \\
\hline 31 & Diphloo & 93.5685556 & 26.6394444 & 31 & 578 & 910 & 303 & 1822 & 84 \\
\hline 32 & Dooria & 93.9191667 & 26.6316667 & 46 & 460 & 927 & 242 & 1675 & 97 \\
\hline 33 & Duklingia & 94.2852151 & 26.6861544 & 74 & 685 & 1329 & 428 & 2515 & 112 \\
\hline 34 & Durrung & 92.7297222 & 26.7227778 & 50 & 445 & 768 & 271 & 1534 & 76 \\
\hline 35 & Furkating & 94.0137903 & 26.4617283 & 55 & 395 & 768 & 318 & 1535 & 106 \\
\hline 36 & Halem & 93.4523611 & 26.8696667 & 44 & 449 & 1022 & 341 & 1856 & 90 \\
\hline 37 & Halmira & 93.9466667 & 26.5241667 & 47 & 468 & 832 & 340 & 1688 & 101 \\
\hline 38 & Harchurah & 92.7537139 & 26.7775488 & 61 & 561 & 1226 & 435 & 2282 & 94 \\
\hline 39 & Hatigarh & 94.0433333 & 26.3888889 & 44 & 452 & 785 & 309 & 1590 & 102 \\
\hline 40 & Hatikhuli & 93.370899 & 26.5848439 & 51 & 540 & 906 & 373 & 1870 & 87 \\
\hline 41 & Kakojan & 94.3886111 & 26.735 & 46 & 440 & 786 & 247 & 1518 & 107 \\
\hline 42 & Kellyden & 92.948746 & 26.483845 & 41 & 440 & 927 & 292 & 1700 & 86 \\
\hline 43 & Keyhung & 95.3279024 & 27.4345426 & 101 & 658 & 1238 & 461 & 2457 & 127 \\
\hline 44 & Khowang & 94.8938766 & 27.2431657 & 80 & 627 & 1052 & 337 & 2096 & 103 \\
\hline 45 & Koomsong & 95.6537533 & 27.6188283 & 109 & 925 & 1182 & 476 & 2693 & 144 \\
\hline 46 & Kopati & 92.25073 & 26.59 & 45 & 504 & 839 & 297 & 1685 & 75 \\
\hline 47 & Lakwa & 94.8722222 & 27.0244444 & 93 & 607 & 1286 & 429 & 2416 & 100 \\
\hline 48 & Lamabari & 92.277784 & 26.842633 & 35 & 504 & 1218 & 408 & 2166 & 134 \\
\hline 49 & Ledo & 95.7683333 & 27.3020278 & 77 & 392 & 577 & 288 & 1333 & 153 \\
\hline 50 & Lengeree & 93.7166667 & 25.9211111 & 41 & 299 & 711 & 302 & 1354 & 154 \\
\hline 51 & Lepetkata & 94.8635316 & 27.3783221 & 222 & 649 & 1113 & 417 & 2402 & 104 \\
\hline 52 & Madhuting & 95.3667005 & 27.3581907 & 27 & 262 & 451 & 157 & 897 & 129 \\
\hline 53 & Mahalakshmi & 93.0608333 & 26.8555556 & 28 & 432 & 733 & 280 & 1473 & 88 \\
\hline 54 & Maijan & 94.9783246 & 27.5079422 & 118 & 623 & 1359 & 529 & 2629 & 111 \\
\hline 55 & Mancotta & 94.9175806 & 27.4385028 & 130 & 865 & 1764 & 653 & 3412 & 108 \\
\hline 56 & Mazbat & 92.2515106 & 26.7810162 & 37 & 559 & 1185 & 379 & 2160 & 113 \\
\hline 57 & Moran & 94.8846352 & 27.1563477 & 72 & 609 & 1060 & 405 & 2146 & 103 \\
\hline 58 & Murphuloni & 93.9247879 & 26.457985 & 36 & 495 & 868 & 295 & 1694 & 106 \\
\hline 59 & Nahorjan & 93.6065063 & 26.6075556 & 62 & 553 & 895 & 302 & 1812 & 98 \\
\hline 60 & Namburnodi & 93.83188 & 26.29877 & 50 & 399 & 731 & 326 & 1506 & 134 \\
\hline 61 & Namdang & 95.7220833 & 27.2655556 & 111 & 730 & 1555 & 534 & 2930 & 427 \\
\hline
\end{tabular}




\begin{tabular}{|c|c|c|c|c|c|c|c|c|c|}
\hline 62 & Namrup & 95.3286111 & 27.1947222 & 50 & 429 & 731 & 256 & 1465 & 125 \\
\hline 63 & Nitinnagar & 94.052032 & 26.345432 & 35 & 294 & 561 & 223 & 1113 & 107 \\
\hline 64 & Nonoi & 92.9216667 & 26.4041667 & 35 & 487 & 1090 & 383 & 1994 & 79 \\
\hline 65 & Ouphulia & 95.0147222 & 27.2177778 & 92 & 704 & 1350 & 493 & 2639 & 109 \\
\hline 66 & Paneery & 91.8962681 & 26.7463385 & 64 & 680 & 1057 & 453 & 2254 & 122 \\
\hline 67 & Panitola & 95.2573121 & 27.4941394 & 95 & 470 & 1087 & 463 & 2114 & 124 \\
\hline 68 & Pavoijan & 93.9055538 & 26.2978396 & 44 & 371 & 654 & 275 & 1344 & 116 \\
\hline 69 & Powai & 95.6482333 & 27.3478431 & 77 & 613 & 1262 & 377 & 2329 & 158 \\
\hline 70 & Rungamatty & 93.8986111 & 26.6702778 & 53 & 543 & 894 & 335 & 1825 & 90 \\
\hline 71 & Rupai & 95.4952778 & 27.6123056 & 111 & 726 & 1313 & 458 & 2608 & 132 \\
\hline 72 & Rupajuli & 92.7217448 & 26.7260395 & 53 & 584 & 1225 & 440 & 2301 & 78 \\
\hline 73 & Sagmootea & 93.004862 & 26.544426 & 49 & 480 & 1013 & 309 & 1851 & 92 \\
\hline 74 & Santi & 95.4125 & 27.3038889 & 102 & 965 & 1368 & 447 & 2882 & 127 \\
\hline 75 & Sepoi & 92.4102034 & 26.7837818 & 17 & 704 & 1077 & 327 & 2125 & 110 \\
\hline 76 & Sepon & 94.845947 & 27.1150673 & 77 & 584 & 1141 & 394 & 2195 & 103 \\
\hline 77 & Sockeiting & 94.087428 & 26.546912 & 57 & 422 & 900 & 314 & 1693 & 98 \\
\hline 78 & Sonabheel & 92.7849483 & 26.7369584 & 48 & 465 & 1045 & 364 & 1921 & 76 \\
\hline 79 & Sundarpur & 95.1924133 & 27.1453118 & 53 & 725 & 1612 & 656 & 3046 & 113 \\
\hline 80 & Teloijan & 94.9437618 & 27.2513485 & 55 & 355 & 798 & 329 & 1537 & 103 \\
\hline 81 & $\begin{array}{l}\text { Tezpore \& } \\
\text { gogra }\end{array}$ & 92.7395976 & 26.7232366 & 61 & 570 & 1030 & 359 & 2020 & 79 \\
\hline 82 & Thanai & 95.0936111 & 27.5357694 & 73 & 576 & 1071 & 396 & 2116 & 116 \\
\hline 83 & Uday jyoti & 93.9638889 & 26.5 & 19 & 383 & 678 & 264 & 1344 & 99 \\
\hline
\end{tabular}

668 Note: DJF = December, January, February

$669 \mathrm{MAM}=$ March, April, May

670 JJA = June, July, August

671 SON $=$ September, October, November

672 
Table 2 Results of homogeneity test

\begin{tabular}{|c|c|c|c|c|c|c|c|c|c|c|}
\hline \multirow{2}{*}{ Case } & \multirow{2}{*}{$\begin{array}{c}\text { Cluster } \\
\text { no. }\end{array}$} & \multicolumn{3}{|c|}{$\mathrm{H}$ test } & \multirow{2}{*}{$\begin{array}{c}\text { Homogeneity } \\
\text { result }\end{array}$} & \multicolumn{3}{|c|}{ After adjustment } & \multirow{2}{*}{$\begin{array}{c}\text { Homogeneity } \\
\text { result }\end{array}$} & \multirow{2}{*}{$\begin{array}{l}\text { Final } \\
\text { no of } \\
\text { sites }\end{array}$} \\
\hline & & H1 & $\mathrm{H} 2$ & H3 & & H1 & $\mathrm{H} 2$ & $\mathrm{H} 3$ & & \\
\hline \multirow{3}{*}{1} & $\mathrm{C} 1$ & -0.08 & -1.25 & -0.99 & $\begin{array}{c}\text { Acceptably } \\
\text { homogeneous }\end{array}$ & 0.68 & -0.97 & -1.06 & $\begin{array}{c}\text { Acceptably } \\
\text { homogeneous }\end{array}$ & 31 \\
\hline & $\mathrm{C} 2$ & 1.08 & -0.69 & 1.1 & $\begin{array}{c}\text { Possibly } \\
\text { heterogeneous }\end{array}$ & 0.49 & -1.04 & 0.9 & $\begin{array}{c}\text { Acceptably } \\
\text { homogeneous }\end{array}$ & 34 \\
\hline & C3 & 2.96 & 1.11 & 0.46 & $\begin{array}{c}\text { Definitely } \\
\text { heterogeneous }\end{array}$ & -0.84 & 0.56 & -0.05 & $\begin{array}{l}\text { Acceptably } \\
\text { homogeneous }\end{array}$ & 16 \\
\hline \multirow{3}{*}{2} & $\mathrm{C} 1$ & -0.98 & -0.73 & 0.04 & $\begin{array}{c}\text { Acceptably } \\
\text { homogeneous }\end{array}$ & -0.91 & -0.62 & 0.1 & $\begin{array}{l}\text { Acceptably } \\
\text { homogeneous }\end{array}$ & 31 \\
\hline & $\mathrm{C} 2$ & 0.54 & -1.25 & 0.09 & $\begin{array}{c}\text { Acceptably } \\
\text { homogeneous }\end{array}$ & 0.41 & -0.71 & 0.39 & $\begin{array}{c}\text { Acceptably } \\
\text { homogeneous }\end{array}$ & 44 \\
\hline & C3 & 1.52 & 0.86 & 0.69 & $\begin{array}{c}\text { Possibly } \\
\text { heterogeneous }\end{array}$ & 0.41 & -1.23 & -1.28 & $\begin{array}{l}\text { Acceptably } \\
\text { homogeneous }\end{array}$ & 7 \\
\hline \multirow{3}{*}{3} & $\mathrm{C} 1$ & 1.86 & 0.91 & 0.15 & $\begin{array}{c}\text { Possibly } \\
\text { heterogeneous }\end{array}$ & 0.71 & 0.85 & -0.11 & $\begin{array}{l}\text { Acceptably } \\
\text { homogeneous }\end{array}$ & 13 \\
\hline & $\mathrm{C} 2$ & -0.88 & -2.24 & -0.25 & $\begin{array}{c}\text { Acceptably } \\
\text { homogeneous }\end{array}$ & 0.73 & -1.95 & 0.16 & $\begin{array}{l}\text { Acceptably } \\
\text { homogeneous }\end{array}$ & 49 \\
\hline & C3 & 1.62 & -0.05 & -0.16 & $\begin{array}{c}\text { Possibly } \\
\text { heterogeneous }\end{array}$ & 0.69 & -0.86 & -0.93 & $\begin{array}{l}\text { Acceptably } \\
\text { homogeneous }\end{array}$ & 21 \\
\hline
\end{tabular}

674

675 


\section{LIST OF FIGURES}

677 Fig. 1 Methodology used to identify homogeneous rainfall regions

678 Fig. 2 Raingauge stations located in various tea gardens of the upper Brahmaputra valley region

679 Fig. 3 Variation in the optimum value of objective function of FCM algorithm with variation of

680 fuzzifier $m$ and cluster number $c$, for (a) Case 1: with total monthly rainfall as attributes; (b) Case 2:

681 with standard deviation of total monthly rainfall as attributes; and (c) Case 3: with latitude, longitude,

682 elevation, total annual rainfall and standard deviation of total annual rainfall as attributes

683 Fig. 4 Clusters formed by the FCM algorithm after adjustment for (a) Case 1: with total monthly

684 rainfall as attributes; (b) Case 2: with standard deviation of total monthly rainfall as attributes; and (c)

685 Case 3: with latitude, longitude, elevation, total annual rainfall and standard deviation of total annual

686 rainfall as attributes

687 


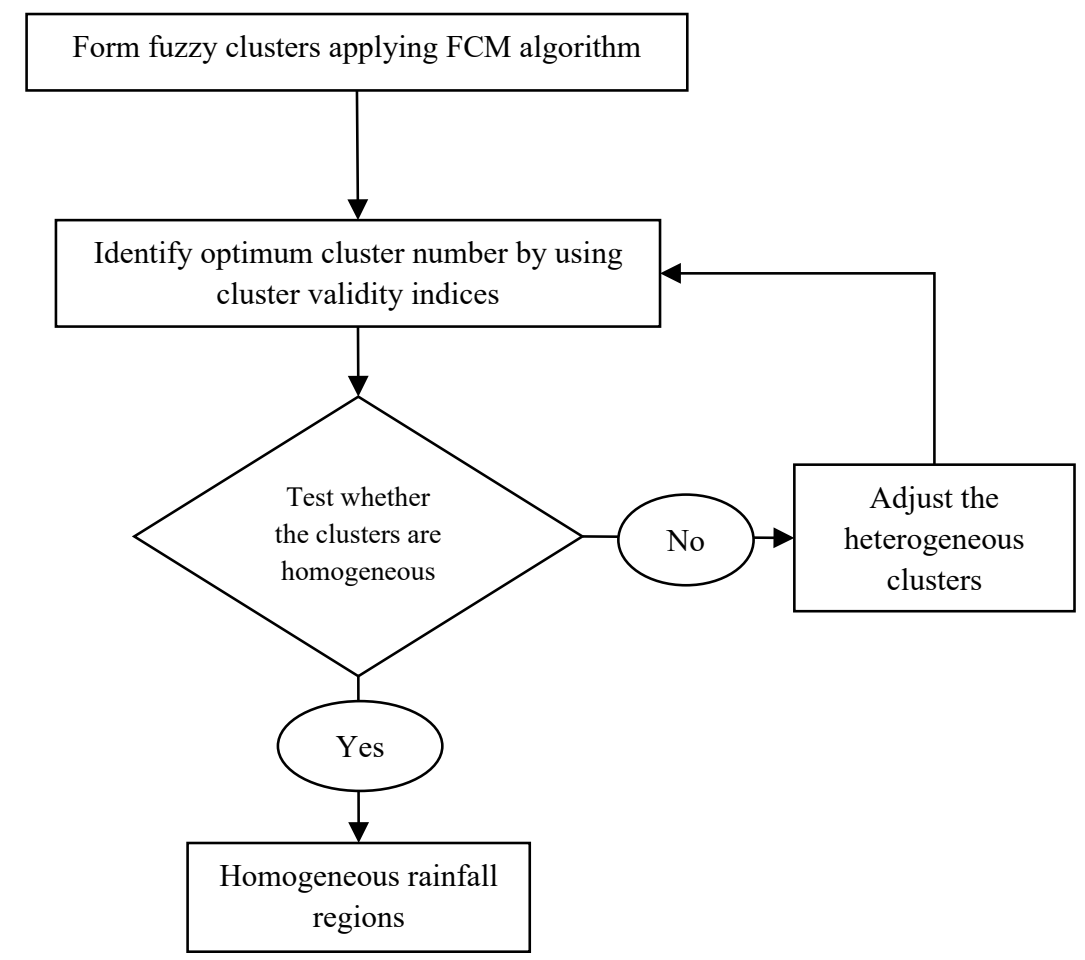

Fig. 1 Methodology used to identify homogeneous rainfall regions 


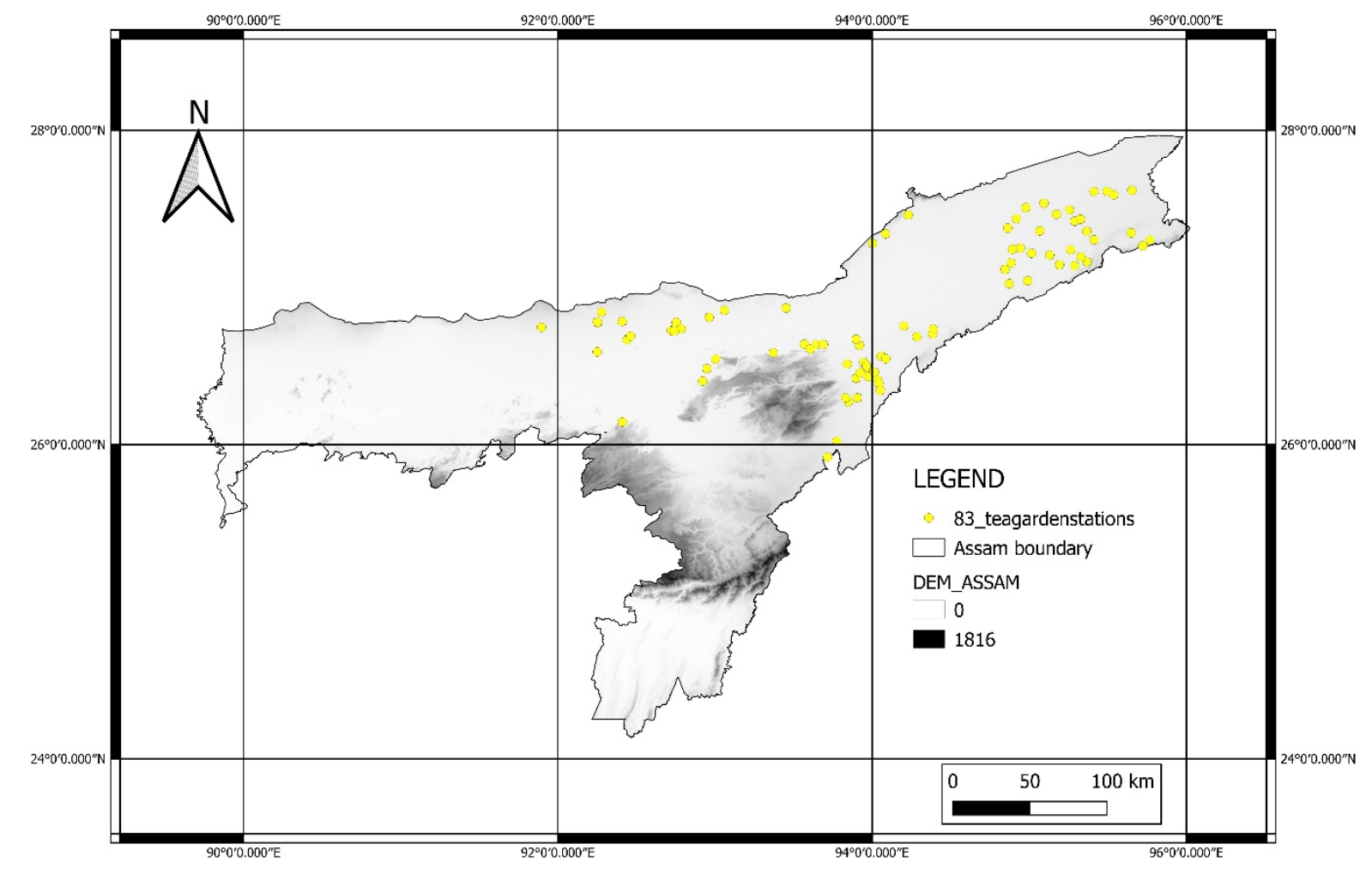

691

Fig. 2 Raingauge stations located in various tea gardens of the upper Brahmaputra valley region 


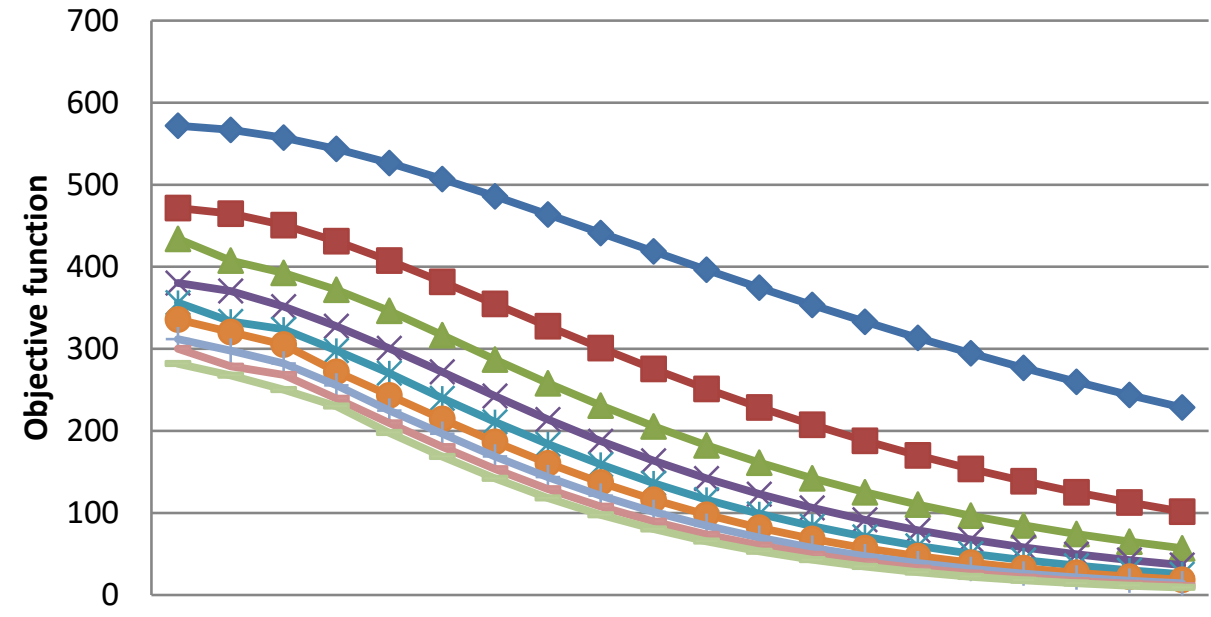

1.11 .21 .31 .41 .51 .61 .71 .81 .9222 .12 .22 .32 .42 .52 .62 .72 .82 .93 Fuzzifier

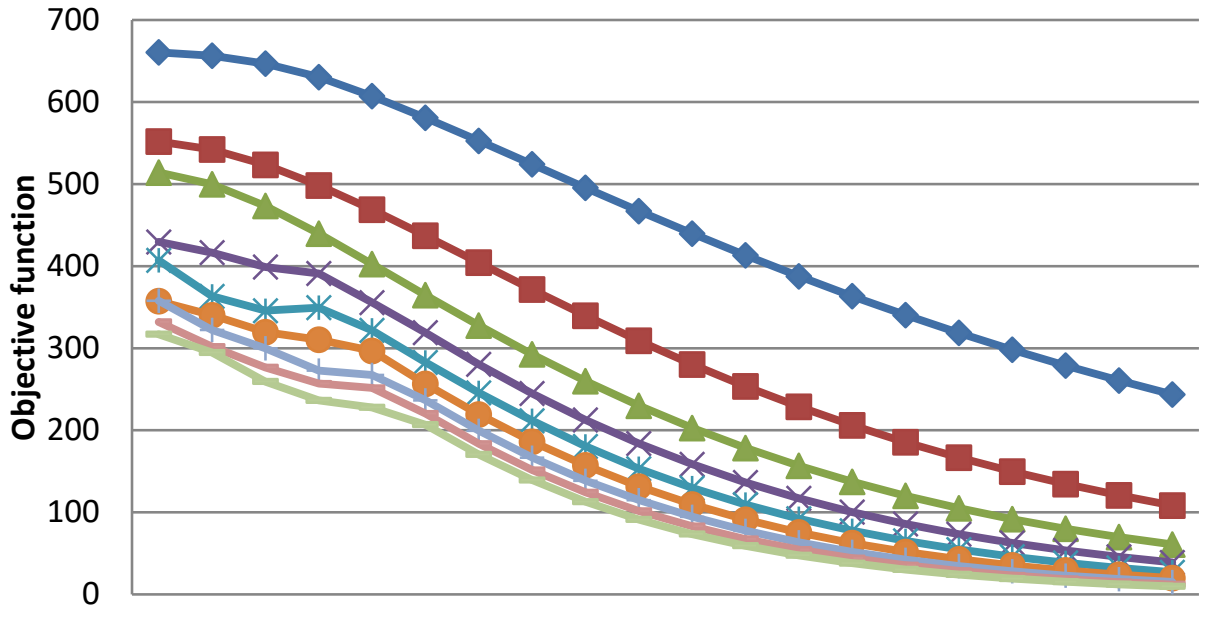

$1.11 .21 .31 .41 .51 .61 .71 .81 .922 \quad 2.12 .22 .32 .42 .52 .62 .72 .82 .9 \quad 3$ no. of cluster $=2$ no. of cluster=3 no. of cluster=4 $\leftarrow$ no. of cluster $=5$ * no. of cluster $=6$ no. of cluster $=7$ no. of cluster=8 no. of cluster $=9$ no. of cluster $=10$ (a) Case 1

Fuzzifier

(b) Case 2 no. of cluster $=2$ no. of cluster=3 no. of cluster $=4$ $\leftarrow$ no. of cluster $=5$ * no. of cluster $=6$ no. of cluster $=7$ - no. of cluster $=8$ no. of cluster $=9$ no. of cluster $=10$ 


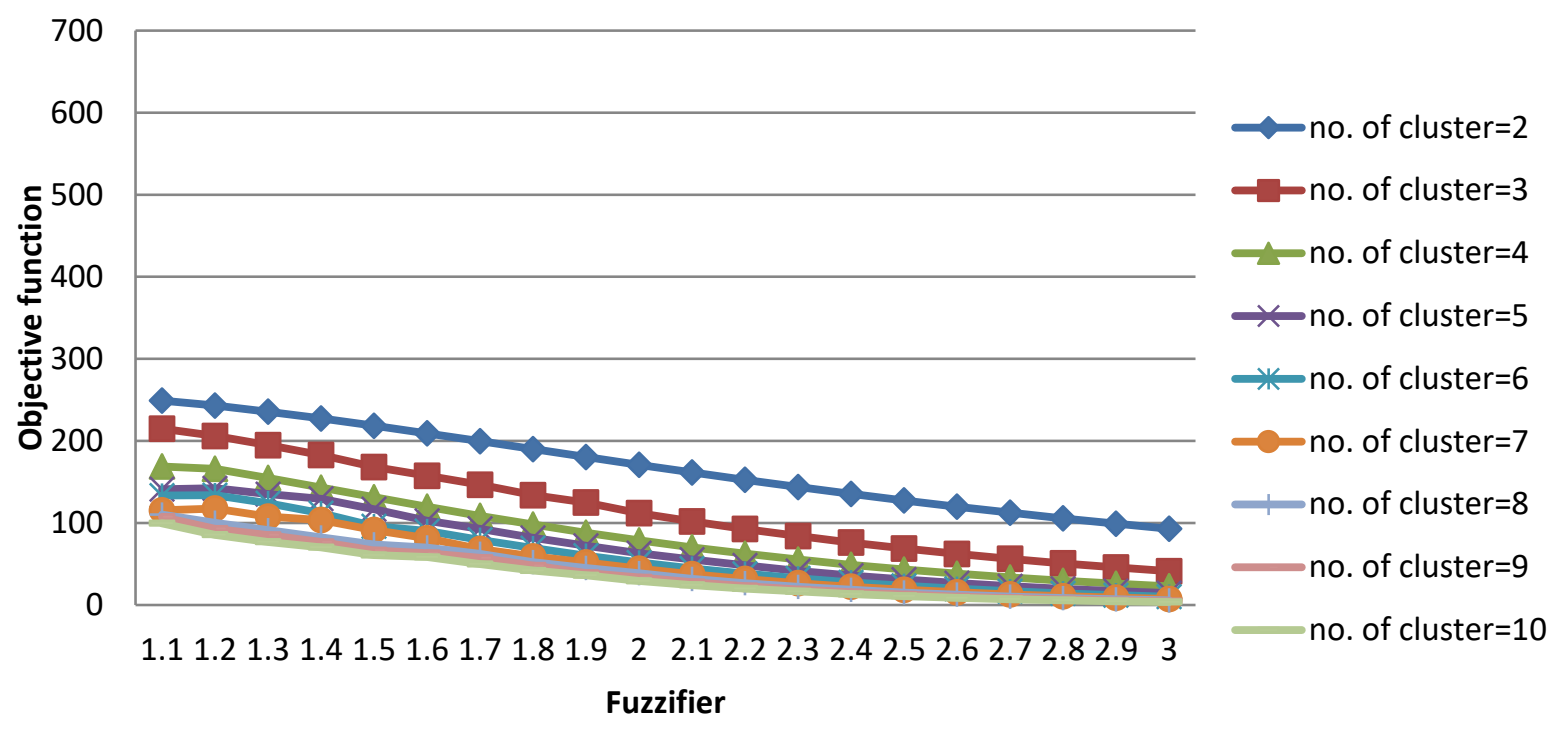

(c) Case 3

Fig. 3 Variation in the optimum value of objective function of FCM algorithm with variation of fuzzifier $m$ and cluster number $c$, for (a) Case 1: with total monthly rainfall as attributes; (b) Case 2: with standard deviation of total monthly rainfall as attributes; and (c) Case 3: with latitude, longitude, elevation, total annual rainfall and standard deviation of total annual rainfall as attributes 


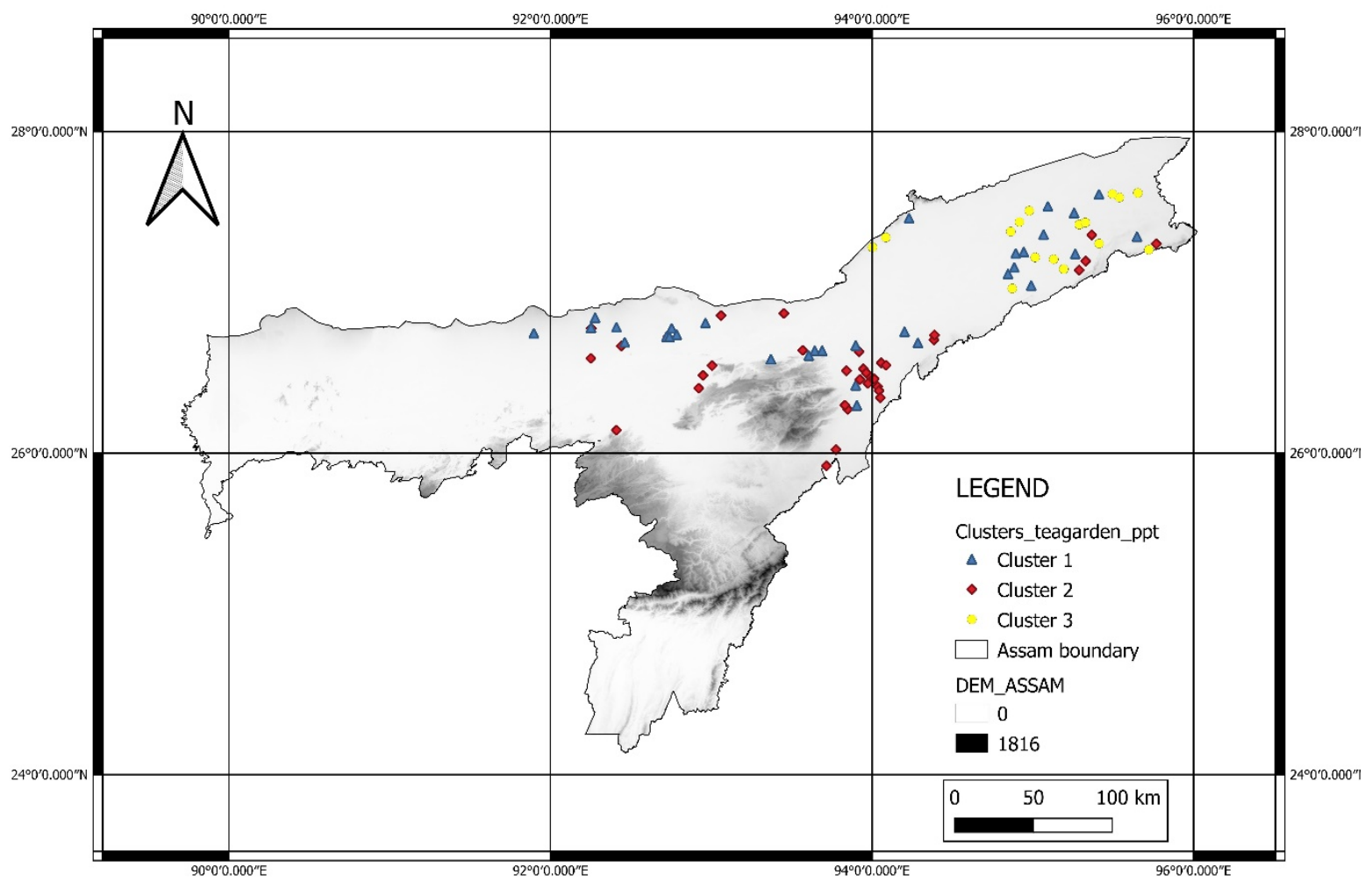

(a) Case 1

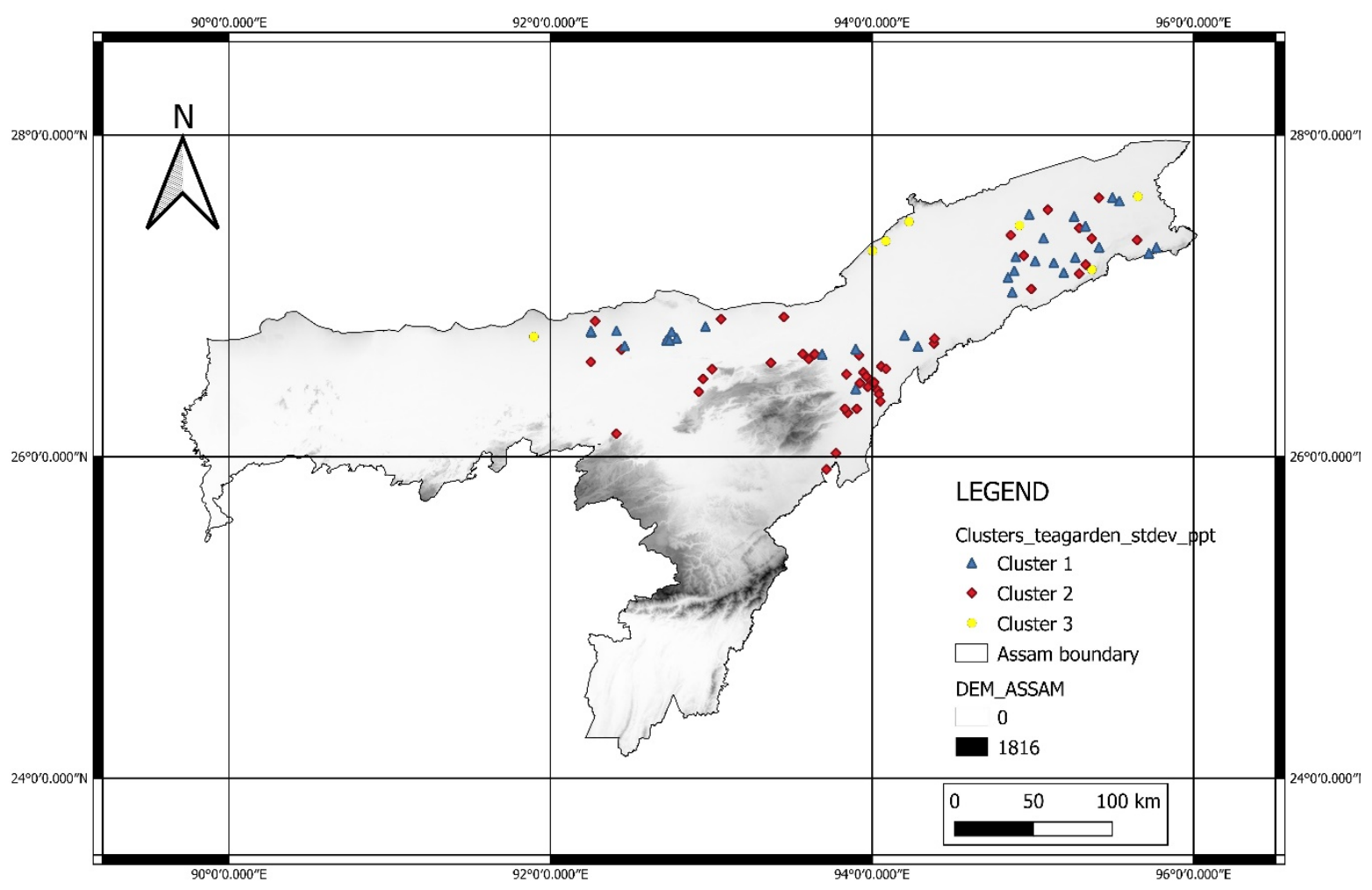


(b) Case 2

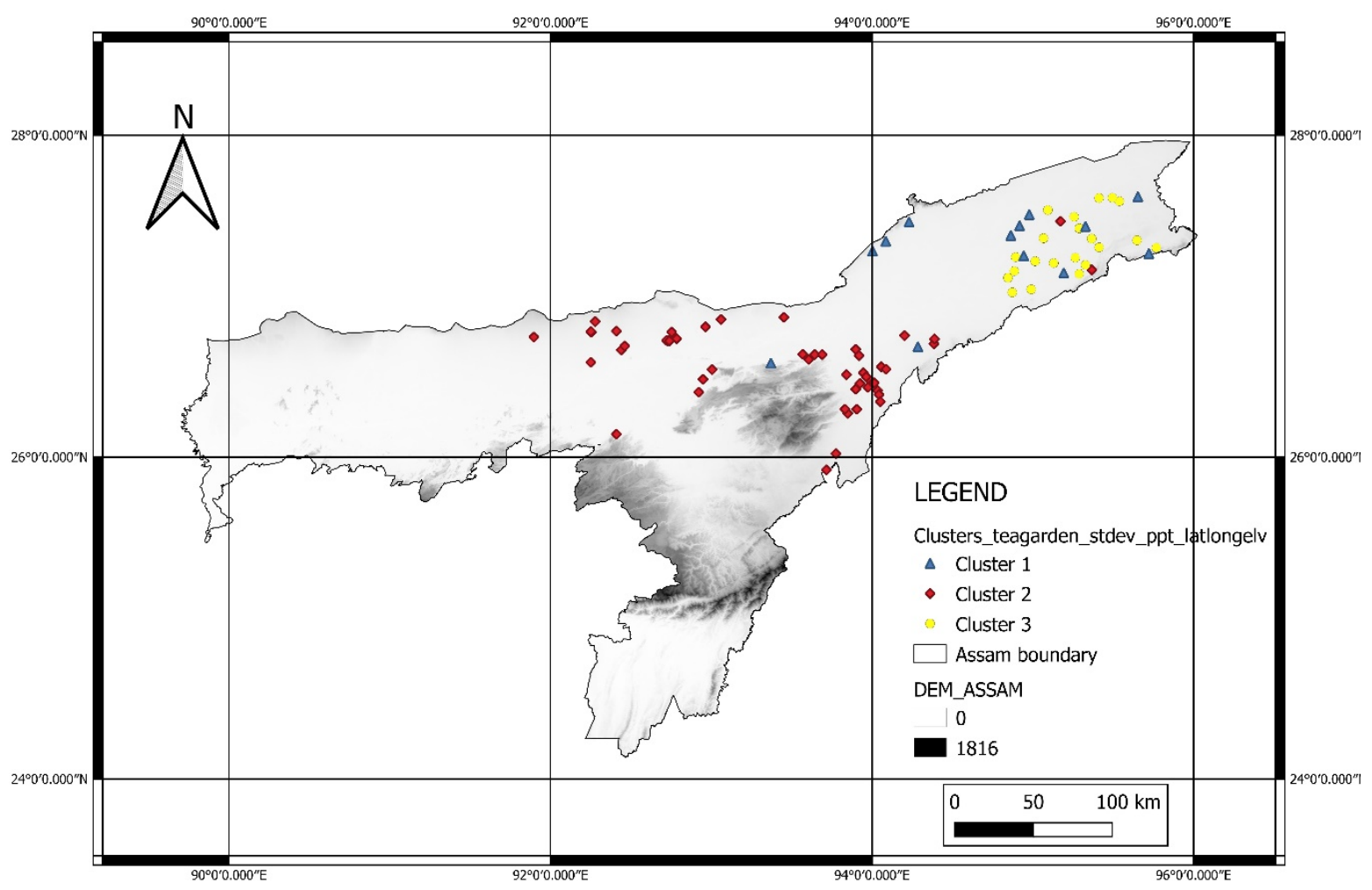

(c) Case 3

699

Fig. 4 Clusters formed by the FCM algorithm after adjustment for (a) Case 1: with total monthly

rainfall as attributes; (b) Case 2: with standard deviation of total monthly rainfall as attributes; and (c) 
Figures

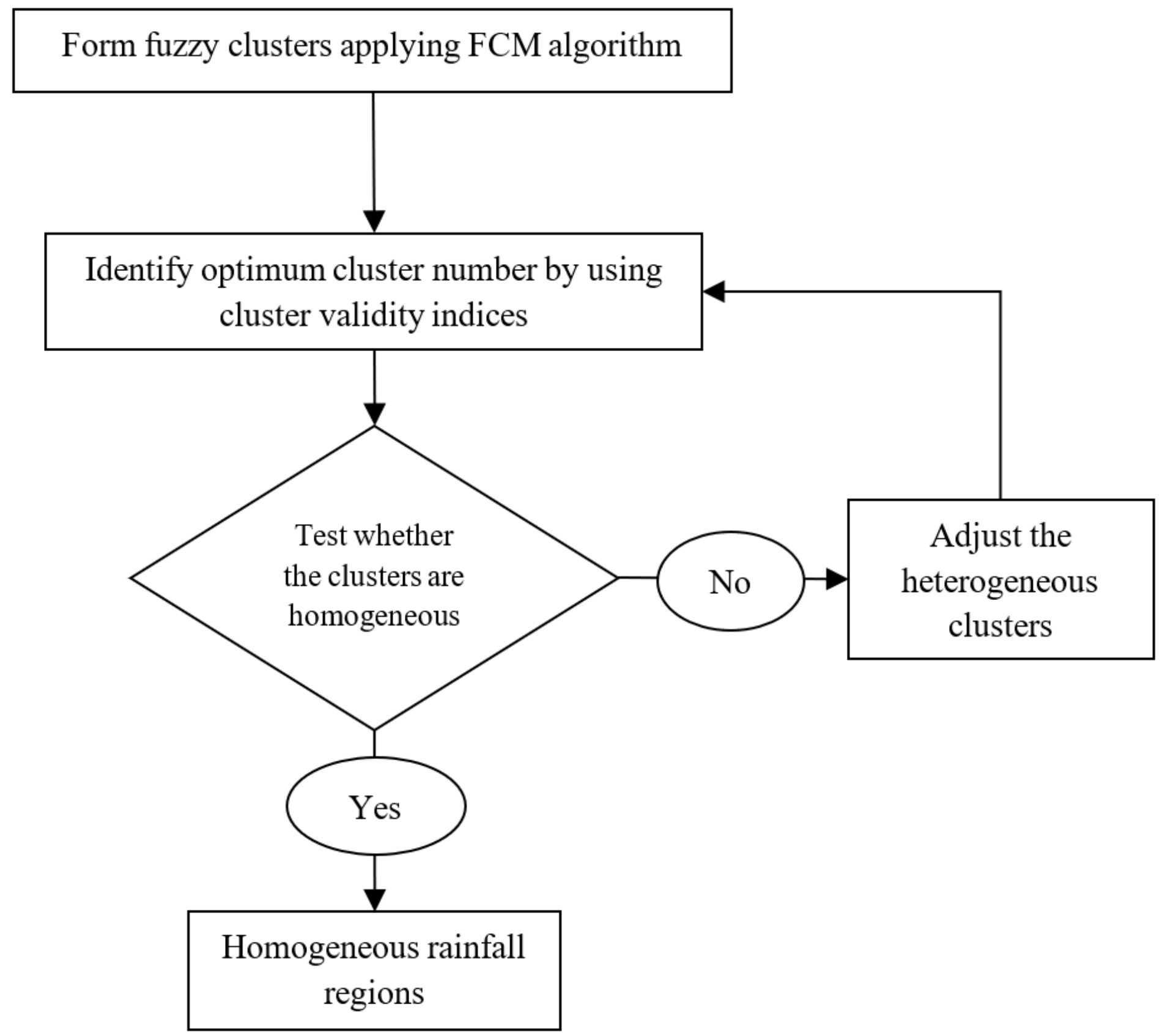

Figure 1

Methodology used to identify homogeneous rainfall regions 


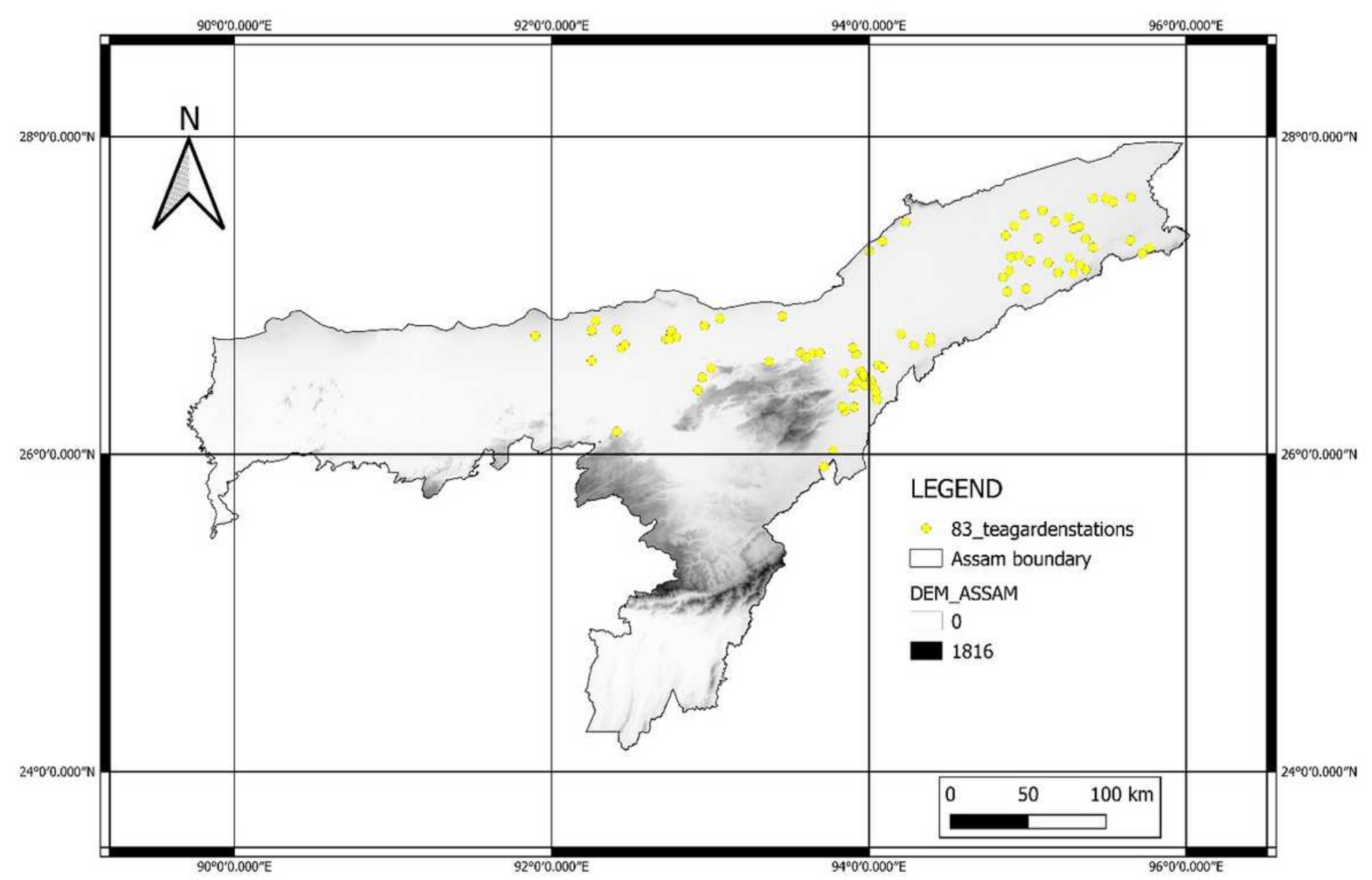

Figure 2

Raingauge stations located in various tea gardens of the upper Brahmaputra valley region. Note: The designations employed and the presentation of the material on this map do not imply the expression of any opinion whatsoever on the part of Research Square concerning the legal status of any country, territory, city or area or of its authorities, or concerning the delimitation of its frontiers or boundaries. This map has been provided by the authors. 


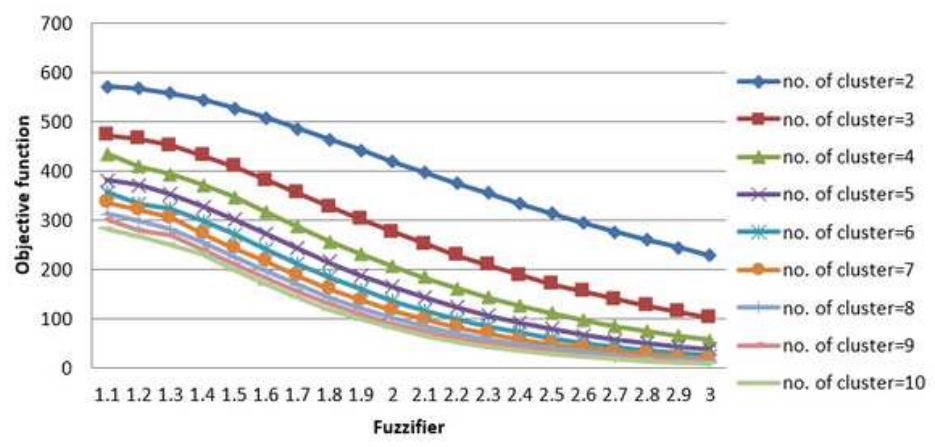

(a) Case 1

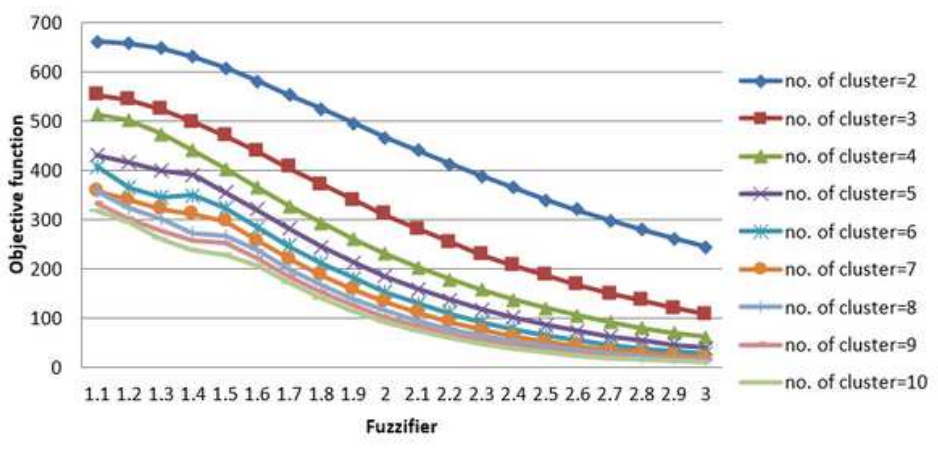

(b) Case 2

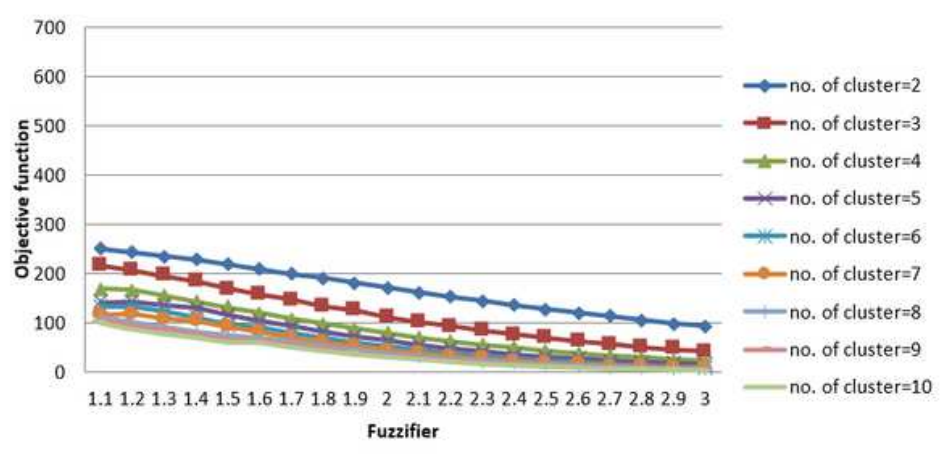

(c) Case 3

\section{Figure 3}

Variation in the optimum value of objective function of FCM algorithm with variation of fuzzifier $\mathrm{m}$ and cluster number c, for (a) Case 1: with total monthly rainfall as attributes; (b) Case 2: with standard deviation of total monthly rainfall as attributes; and (c) Case 3: with latitude, longitude, elevation, total annual rainfall and standard deviation of total annual rainfall as attributes 


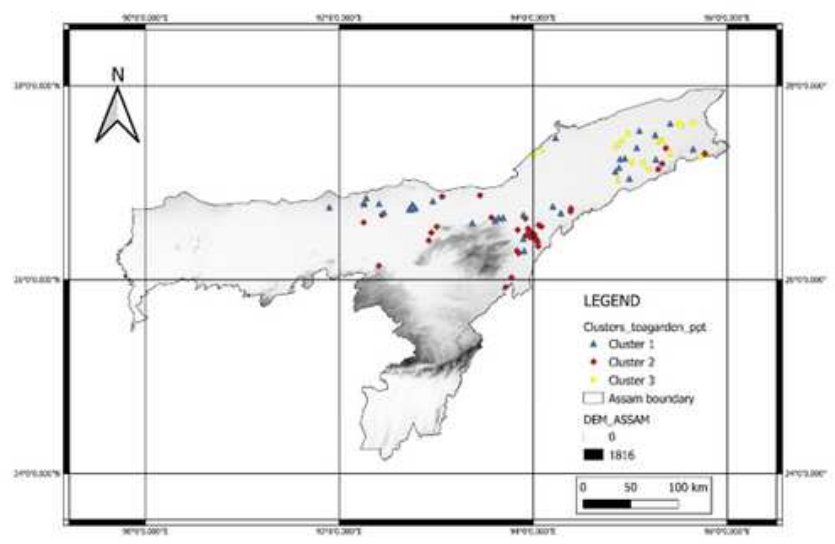

(a) Case 1

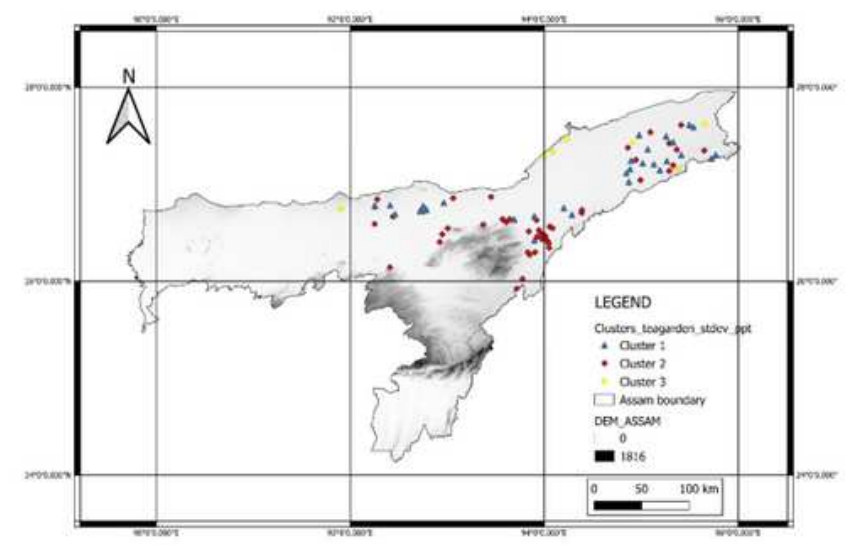

(b) Case 2

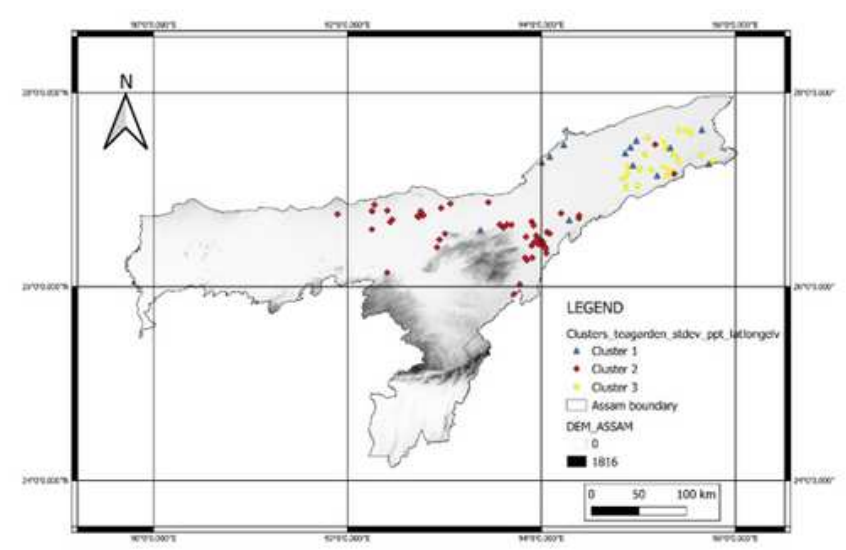

(c) Case 3

\section{Figure 4}

Clusters formed by the FCM algorithm after adjustment for (a) Case 1: with total monthly rainfall as attributes; (b) Case 2: with standard deviation of total monthly rainfall as attributes; and (c) Case 3: with latitude, longitude, elevation, total annual rainfall and standard deviation of total annual rainfall as attributes. Note: The designations employed and the presentation of the material on this map do not imply the expression of any opinion whatsoever on the part of Research Square concerning the legal 
status of any country, territory, city or area or of its authorities, or concerning the delimitation of its frontiers or boundaries. This map has been provided by the authors.

\section{Supplementary Files}

This is a list of supplementary files associated with this preprint. Click to download.

- SupplementaryMaterial.docx 